\title{
MicroRNAs as Important Players in Host-hepatitis B Virus Interactions
}

\author{
Bouchra Kitab ${ }^{1}$, Hanane Salih Alj $^{2}$, Sayeh Ezzikouri ${ }^{1}$ and Soumaya Benjelloun*1 \\ ${ }^{1}$ Viral Hepatitis Laboratory, Virology Unit, Institut Pasteur du Maroc, Casablanca, Morocco; ${ }^{2}$ Laboratory of Biology and Health, \\ URAC34, Faculty of Sciences Ben M'sik, University Hassan II Casablanca, Morocco
}

\begin{abstract}
Hepatitis B virus (HBV) infection, a major public health problem, causes acute and chronic hepatitis that is often complicated by liver cirrhosis and hepatocellular carcinoma. The pathogenic mechanisms of HBV-related liver disease are not well understood, and the current licensed therapies are not effective in permanently clearing virus from the circulation. In recent years, the role of micro-ribonucleic acids (miRNAs) in HBV infection has attracted great interest. Cellular miRNAs can influence HBV replication directly by binding to HBV transcripts and indirectly by targeting cellular factors relevant to the HBV life cycle. They are also involved in the regulation of cellular genes and signaling pathways that have critical roles in HBV pathogenesis. HBV infection, in turn, can trigger changes in cellular miRNA expression that are associated with distinctive miRNA expression profiles depending on the phase of liver disease. These alterations in miRNA expression have been linked to disease progression and hepatocarcinogenesis. We provide here an up to date
\end{abstract}

Keywords: MicroRNA; Hepatitis B virus; Host-virus interaction; Gene expression; Biomarker.

Abbreviations: 3'-UTR, 3'-untranslated region; AFP, alpha-fetoprotein; AGO2, argonaute 2 protein; ALT, alanine aminotransferase; AUC, area under the curve; cCCDNA, covalently closed circular DNA; $\mathrm{CCl}_{4}$, carbon tetrachloride; C/EBP, CCAAT enhancer-binding protein; CHORDs, cysteine- and histidine-rich domain; DGCR8, DiGeorge syndrome critical region 8; DNMT, DNA methyltransferase; ECM, extracellular matrix; ER- $\alpha$, estrogen receptor alpha; FNDC3B, fibronectin type III domain containing $3 B$; FXR $\alpha$, farnesoid $X$ receptor $\alpha$; HBCAg, hepatitis $B$ core antigen; $\mathrm{HBeAg}$, hepatitis $B$ early antigen; $\mathrm{HBsAg}$, hepatitis $B$ surface antigen; $\mathrm{HBV}$, hepatitis $B$ virus; $\mathrm{HBX}$, hepatitis $\mathrm{B} X$ protein; $\mathrm{HBXIP}, \mathrm{HBX}$-interacting protein; HCC, hepatocellular carcinoma; HDAC4, histone deacetylases-4; HDAd, helper dependent adenoviral vectors; HLA-A, human leukocyte antigen A; HNF, hepatocyte nuclear factor; HO-1, heme oxygenase-1; HSCs, hepatic stellate cells; IFN$\alpha /$ PEG-IFN- $\alpha$, pegylated interferon alpha; IL-6, interleukin-6; JAK/STAT, Janus kinase/signal transducer and activator of transcription; LC, liver cirrhosis; LHBsAg, large HBsAg; Mcl-1, myeloid cell leukemia sequence $1 ;$ MHBsAg, middle HBsAg; miRNA, microRNA; mTOR, mammalian target of rapamycin; NDRG3, $\mathrm{N}$-myc downstream-regulated gene 3; NFIB, nuclear factor I/B; NF-кb, nuclear factor kappa B; nt, nucleotides; ORF, open reading frames; P-bodies, processing bodies; PI3K, phosphatidylinositol 3-kinase; pgRNA, pregenomic RNA; Pol II, polymerase II; PPAR $\alpha$, peroxisome proliferator-activated receptor- $\alpha$; pre-miRNAs, precursor miRNAs; PTEN, phosphatase and tensin homolog; PTTG1, pituitary tumor-transforming gene 1 ; RASSF1A, ras-associated domain family member 1A; RISC, RNA-induced silencing complex; RLC, RISC loading complex; ROC, receiver operating characteristic; SHBsAg, small HBsAg; TALENs, transcription activator like effecter nucleases; TGF- $\beta$, transforming growth factor- $\beta$; TLR, toll-like receptor; TRBP, transactivation-response RNA-binding protein.

Received: 21 January 2015; Revised: 09 March 2015; Accepted: 09 March 2015 DOI: $10.14218 /$ JCTH.2015.00002.

*Correspondence to: Soumaya Benjelloun, Virology Unit, Institut Pasteur du Maroc, 1 Place Louis Pasteur, Casablanca 20360, Morocco. Tel: +212-527-016-076; +212-522-434-450, Fax: +212-522-260-957, E-mail: soumaya.benjelloun@ pasteur.ma review regarding the field of miRNAs and HBV interplay and highlight the potential utility of miRNAs as diagnostic biomarkers and therapeutic targets for the management of HBV-related liver disease.

(C) 2015 The Second Affiliated Hospital of Chongqing Medical University. Published by XIA \& HE Publishing Ltd. All rights reserved.

\section{Introduction}

Hepatitis B virus (HBV) is a prototype member of the Hepadnaviridae family and one of most common human pathogens worldwide. Despite the availability of an effective prophylactic vaccine for nearly three decades, HBV remains the cause of a number of important public health problems. ${ }^{1} \mathrm{HBV}$ is transmitted among humans by contact with the blood or other bodily fluids of an infected person and is commonly acquired through perinatal, horizontal, sexual, and parenteral/ percutaneous transmission. The clinical manifestations of HBV infection range from acute or fulminant hepatitis to various forms of chronic infection, which may evolve to liver cirrhosis and hepatocellular carcinoma (HCC). ${ }^{2}$ According to World Health Organization estimates, more than 240 million people worldwide have chronic hepatitis $B$, and more than 780,000 people die annually due to the acute or chronic complications of hepatitis B. ${ }^{3}$ At present, two types of antiviral drugs are approved for the treatment of chronic hepatitis $B$, including conventional or pegylated interferon alpha (IFN- $\alpha$ or PEG-IFN- $\alpha$ ) and nucleos(t)ide analogs. ${ }^{4}$ IFN- $\alpha$ or PEG-IFN- $\alpha$ have significant toxicity. Nucleos(t)ide analogs have limited success in achieving sustained virological response and are susceptible to drug resistance. ${ }^{4,5}$ Growing evidence has highlighted the importance of investigating the interactions between HBV and the host in order to understand better the mechanisms of HBV pathogenesis and to develop novel and improved anti-HBV therapeutic strategies. ${ }^{6,7}$

Recent findings about the role of micro-ribonucleic acids (miRNAs/miRs) in various aspects of HBV-host interactions have added another dimension to our understanding of HBV pathogenesis. MiRNAs represent a large class of highly conserved noncoding RNAs of $\sim 22$ nucleotides (nt) in length, which modulate gene expression at the post-transcriptional level. They bind to the $3^{\prime}$-untranslated region (3'-UTR) of target messenger RNAs (mRNAs), resulting in gene silencing through translational repression or mRNA degradation. ${ }^{8}$ First discovered in the nematode Caenorhabditis elegans, miRNAs have been identified in all multicellular eukaryotes and some viruses. ${ }^{9-11}$ MiRNAs modulate HBV replication and host responses. Therefore, exploring the function of miRNAs and 
Kitab B. et al: MicroRNAs and HBV infection

their application in therapeutics and diagnostics has become an emerging area of interest in the field of HBV research. In the current review, we will describe the current knowledge regarding the biological relevance of miRNAs in the context of HBV infection. We will also discuss the potential value of miRNAs as diagnostic biomarkers and therapeutic targets for HBV-related liver disease.

\section{miRNAs biogenesis and functions}

The biogenesis of miRNAs involves numerous critical steps that occur in both the nucleus and cytoplasm. The genes encoding miRNAs can be mono- or polycistronic and are frequently located in intergenic regions of genomes and introns of protein-coding or noncoding genes. ${ }^{12,13}$ Generally, miRNA genes are transcribed by RNA polymerase II (Pol II) as large primary transcripts (pri-miRNAs) that contain a stemloop structure of $\sim 80 \mathrm{nt}^{14}$ Pri-miRNAs are then processed by the RNaseIII-like enzyme Drosha together with its binding partner DiGeorge syndrome critical region 8 (DGCR8), to produce the $\sim 60-70$ nt precursor miRNAs (pre-miRNAs). ${ }^{15}$ These are transported into the cytoplasm by Exportin-5 via a RanGTP-dependent mechanism. ${ }^{15,16}$ Once in the cytoplasm, pre-miRNAs are processed by Dicer, another RNaseIII-like enzyme, and transactivation-response RNA-binding protein (TRBP) to generate the $\sim 22 \mathrm{nt}$ duplexes comprising the mature miRNAs and the complementary fragments miRNAs*. ${ }^{17}$ Mature miRNAs are connected to the RNA-induced silencing complex (RISC), whereas miRNAs* are rapidly degraded. ${ }^{18}$ TRBP, Argonaute 2 protein (AGO2), and Dicer are involved in the formation of the RISC loading complex (RLC), which can facilitate the binding of the mature miRNAs to RISC. ${ }^{19,20}$ Finally, mature miRNAs guide RISC to complementary sites within the target mRNAs to execute the post-transcriptional regulatory activity. In the case of perfect sequence complementarity between target mRNAs and miRNAs, mRNAs are degraded by RISC, whereas in the case of partial sequence complementarity, a repression of mRNA translation occurs. ${ }^{21,22}$ Evidence also indicates that miRNA-bound transcripts are sequestered into processing bodies (P-bodies), where they are maintained in a silenced state. ${ }^{23}$ Thus, P-bodies serve as a site of temporary storage before mRNA degradation or translational inhibition. ${ }^{23}$

The human genome encodes 2,565 miRNAs (miRBase ver. 21; http://www.mirbase.org/, released in June 2014). Each miRNA can regulate hundreds of different mRNAs, and conversely, a single mRNA can be targeted by several miRNAs. Bioinformatic analyses have indicated that more than $30 \%$ of human genes are under miRNA-mediated regulation. ${ }^{24}$ Accordingly, cellular miRNAs play an important role in several biological and physiological processes, such as cell differentiation, proliferation, metabolism, apoptosis, developmental timing, and immune responses. ${ }^{25}$ Deregulation of their expression and function is also involved in various diseases, especially cancers. ${ }^{26,27}$ In viral infections, cellular miRNAs can positively or negatively influence virus replication by regulating the expression of viral genes and/or cellular factors relevant to the course of virus-induced disease. ${ }^{28}$ At the same time, viruses can alter cellular miRNA expression. In fact, viruses are equipped with complex machinery to exploit and manipulate the host pathways to establish an environment favorable for their persistence. ${ }^{29}$ It is not surprising, therefore, that the miRNA pathway can be used to do this, either by encoding their own miRNAs or encoding molecules that inhibit or stimulate cellular miRNA expression. ${ }^{30}$

\section{miRNAs in HBV replication}

HBV has a relaxed circular, partially double-stranded (RC-DNA) genome containing four overlapping open reading frames (ORF). ${ }^{31}$ The preS/S ORF encodes three viral surface proteins [large hepatitis B surface antigen (LHBsAg), middle HBsAg (MHBsAg), and small HBsAg (SHBsAg)], the preC/C ORF encodes the core protein (hepatitis $B$ core antigen $(\mathrm{HBcAg}))$ and the soluble e protein (hepatitis $B$ early antigen $(\mathrm{HBeAg})$ ), the $X$ ORF encodes the hepatitis $B X$ protein (HBX), and the Pol ORF encodes the viral polymerase that possesses DNA polymerase and reverse transcriptase activities. ${ }^{31}$ After infecting hepatocytes, the HBV genome is released into the nucleus and converted to covalently closed circular DNA (cccDNA), which serves as a template for the transcription of all viral transcripts, including pregenomic RNA (pgRNA) and subgenomic RNAs (pre-S, S and X mRNAs). ${ }^{32}$ The transcription of viral transcripts is regulated by four distinct viral promoters that are under the control of two regulators, designated enhancers I and II. ${ }^{33}$ In addition, a variety of liverenriched transcription factors and nuclear receptors have been shown to bind to HBV promoter/enhancer elements and to be critical for the regulation of HBV transcription. ${ }^{33,34}$ Viral miRNAs encoded by HBV have not been identified, but one putative HBV-encoded pre-miRNA was predicted using computational approaches. ${ }^{35}$ Nevertheless, numerous cellular miRNAs have emerged that either repress or promote HBV replication by direct interaction with HBV transcripts or indirectly by targeting crucial cellular factors relevant to HBV life cycle (Fig. 1).

\section{miRNAs suppressing HBV replication}

The first attempt to search for miRNAs that directly target HBV transcripts was made by Zhang et al., using a miRNAloss-of-function approach. ${ }^{36}$ A total of 328 human miRNAs were individually knocked-down in HepG2.2.15 cells that are designed to support the HBV life cycle. ${ }^{36}$ Among these, miR199a-3p and miR-210 efficiently reduced HBsAg expression and HBV replication. Bioinformatics analysis revealed that miR-199a-3p and miR-210 inhibited HBV by directly targeting the HBsAg encoded region and the pre-S1 region of the HBV genome, respectively. ${ }^{36}$ The ability to affect HBsAg expression was also demonstrated for miR-125a-5p, which binds to HBsAg mRNA and inhibits its translation. ${ }^{37}$ Another study revealed a self-inhibitory feedback loop where $\mathrm{HBV}$, through $\mathrm{HBx}$, increased the expression of miR-125a-5p and subsequently interfered with HBsAg expression. ${ }^{38}$ Furthermore, extensive studies reported a remarkable decrease in HBV replication when the expression of miR-122, the most abundant liver-specific miRNA, was upregulated in both cell lines and liver tissues. ${ }^{39-41}$ These studies proposed several mechanims underlying miR-122-mediated suppression of HBV replication. Chen et al. found that miR-122 binds to a highly conserved sequence of HBV pgRNA, which is a bicistronic mRNA encoding the viral polymerase and core protein, resulting in a decrease in HBV core-associated DNA level. ${ }^{39}$ Qiu et al. suggested that miR-122 inhibited HBV replication through increasing expression of cellular heme oxygenase-1 (HO-1), a cytoprotective enzyme that decreases HBV cccDNA levels both in vitro and in vivo. ${ }^{40}$ Another regulatory mechanism of 


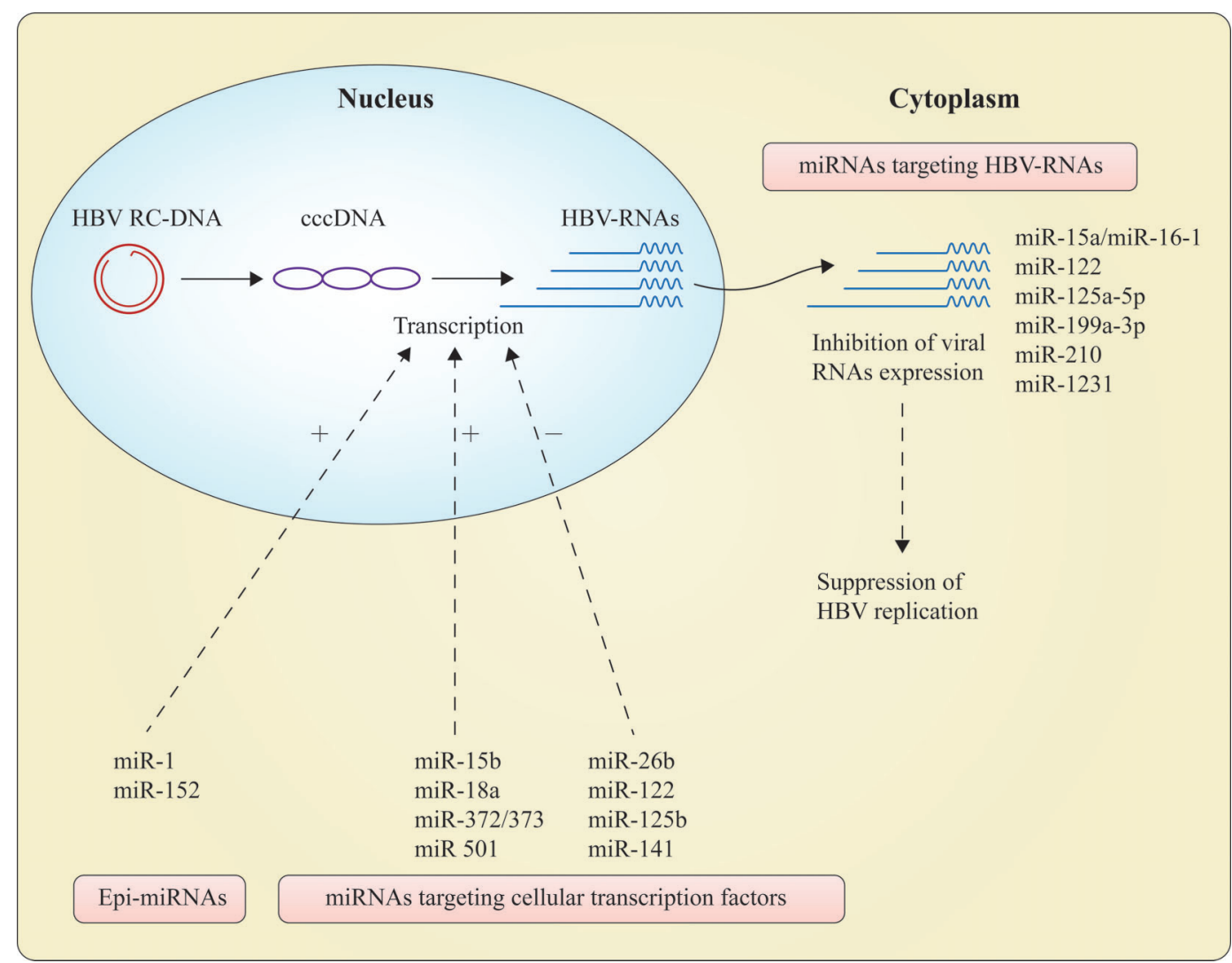

Fig. 1. Summary of cellular miRNAs involved in the regulation of HBV replication. MiRNAs may suppress $(-)$ or promote $(+)$ HBV replication by targeting positive or negative cellular transcription factors, critical for HBV transcription. Epi-miRNAs contribute to increased synthesis of HBV transcripts by regulating epigenetic modifications of HBV covalently closed circular DNA (cccDNA). Other cellular miRNAs directly target HBV-RNAs and suppress viral proteins expression.

miR-122 involved cyclin G1-modulated p53 activity. ${ }^{41}$ Cyclin G1 specifically interacted with $\mathrm{p} 53$, and this interaction blocks the binding of p53 to HBV enhancers, subsequently abrogating p53-mediated inhibition of HBV transcription. ${ }^{42}$ However, cyclin G1 was targeted by miR-122, thereby promoting the anti-HBV activity of p53. ${ }^{41}$ Reduced HBV replication has been also observed in presence of high miR-1231 levels in HBV-transfected HepG2 cells. ${ }^{43}$ Extensive analysis revealed that miR-1231 targeted HBV core and HBx sequences, resulting in decreased expression of HBV core protein with no reduction in $\mathrm{HBx}$ protein. ${ }^{43}$ Other viral sequences critical for HBV replication, including the coding region for HBV polymerase and the overlapping region between HBV polymerase and $\mathrm{HBx}$, were shown as potential targets for miR-15a/miR-16-1 cluster. $^{44}$ The antiviral effect of miR-15a/ miR-16-1 was validated in vitro, showing a negative correlation between the expression of this cluster and HBV replication in HBV-transfected HepG2 cells. ${ }^{44}$

Besides miRNAs targeting HBV transcripts, other miRNAs elicit their antiviral activity by targeting a positive regulator of HBV. The peroxisome proliferator-activated receptor- $\alpha$ $(P P A R \alpha)$, which binds and transactivates HBV promoters, was described as a target of miR-141. ${ }^{45}$ Tranfection of synthetic miR-141 in HBV-transfected HepG2 cells suppressed PPAR $\alpha$ expression, leading to reduced HBV transcription. ${ }^{45}$ The role of the CCAAT enhancer-binding protein (C/EBP) in transactivation of HBV enhancer II, core, and S promoters was abolished by miR-155, which targets and downregulates
C/EBP, thereby repressing HBV replication. ${ }^{46,47}$ Recently, it was reported that elevated miR-26a levels in hepatoma cells resulted in a marked decrease in HBV-DNA and protein expression. ${ }^{48}$ Subsequent analysis demonstrated that miR$26 \mathrm{~b}$ inhibited the expression of cysteine- and histidine-rich domain containing 1 (CHORDC1), which functions as a positive regulator of $\mathrm{HBV}$ enhancer/promoter activities. ${ }^{48}$ Targeted inhibition by miR-125b of another cellular factor, the sodium channel nonvoltage-gated 1 alpha (SCNN1A), repressed HBV protein expression. ${ }^{49}$ However, the mechanism by which SCNN1A affects HBV replication is not wellknown and needs further investigation. ${ }^{49}$

\section{miRNAs promoting HBV replication}

For miRNAs that promote HBV replication, it appears they share a common pattern of targeting negative cellular regulators of HBV replication. HBX-interacting protein (HBXIP) was originally isolated as a human protein that binds to $\mathrm{HBX}$ protein and may reduce HBV replication by interacting with a domain necessary for HBx transactivation. ${ }^{50}$ However, HBXIP was identified as a putative target of miR-501, and its expression was inversely correlated with miR-501 expression in HepG2.2.15 cells. ${ }^{51}$ Moreover, downregulation of miR-501 significantly inhibited HBV-DNA replication, and HBXIP knockdown rescued the inhibition of HBV with miR-501 loss in HepG2.2.15 cells, suggesting that miR-501 enhanced HBV replication by targeting HBXIP. ${ }^{51} \mathrm{~A}$ negative correlation was 
Kitab B. et al: MicroRNAs and HBV infection

also identified between miR-372/373 and nuclear factor I/B (NFIB), a transcription factor that downregulates HBV enhancer I and core promoter activities. ${ }^{52}$ High expression of miRs-372/373 reduced endogenous NFIB levels in HepG2 cells. Further analysis of the $3^{\prime}$-UTR of NFIB mRNA revealed two predicted sites for miR-372/373. ${ }^{52}$ In addition, knockdown of NFIB in HepG2 cells resulted in increased HBV gene expression, whereas enhanced expression of miR-372/373 stimulated the production of HBV proteins. ${ }^{52}$ Taken together, these findings indicated that miR-372/373 can promote HBV expression through a pathway involving NFIB. Another negative regulator of HBV enhancer I activity, the hepatocyte nuclear factor $1 \alpha(\mathrm{HNF} 1 \alpha)$, was recently described as a mediator in miRNA promotion of HBV replication. ${ }^{53}$ HNF $1 \alpha-m R N A$ was directly downregulated by miR-15b, resulting in transactivation of HBV Enhancer I. ${ }^{53}$ However, it has been shown that increased expression of HBV proteins, especially $\mathrm{HBx}$, resulted in downregulation of miR-15b expression in both HBV-producing cells and an HBV transgenic mouse model. ${ }^{53}$ This reciprocal regulation between miR-15b and HBV may help to control the level of HBV replication. Moreover, dysregulation of the estrogen pathway by miRNAs may be an important mechanism underlying the regulation of HBV replication. The estrogen pathway can reduce HBV replication by enhancing the expression of estrogen receptor alpha $(E R-\alpha)$, which interacts with hepatocyte nuclear factor 4 alpha (HNF-4 $\alpha$ ), and preventing HNF- $4 \alpha$ binding to the HBV enhancer I and activation of HBV transcription. ${ }^{54}$ For instance, miR-18a has been shown to repress ER $\alpha$ translation by binding to its mRNA, thus promoting HBV transcription. ${ }^{55}$

Epigenetic modifications of HBV cccDNA, such as DNA methylation and deacetylation, play a pivotal role in the control of HBV replication by suppressing ccCDNA transcription to viral mRNAs. ${ }^{56}$ Epi-miRNAs, including miR-1 and miR-152, have been recently implicated in the regulation of epigenetic modifications of HBV cccDNA. In a study by Zhang et al., miR-1 was shown to directly target histone deacetylases-4 (HDAC4), and transfection of miR-1 in HepG2.2.15 cells led to markedly reduced expression of histone deacetylases-4 (HDAC4) and enhanced HBV transcription. ${ }^{57}$ Furthermore, cotransfection of an HDAC4 expression vector with miR-1 attenuated HBV mRNAs levels. These findings indicated that HDAC4 plays a significant role in the action of miR-1 on HBV replication. ${ }^{57}$ The modulation of HDAC4 expression by miR-1 may lead also to enhanced expression of farnesoid $X$ receptor $\alpha(F X R \alpha)$, resulting in a marked increase in HBV-DNA and proteins levels by enhancing transcriptional activity of the HBV core promoter. ${ }^{57,58}$ Regarding miR-152, its expression was shown to be inversely correlated with DNA methyltransferase (DNMT1) expression in liver cell lines. In silico predictions defined DNMT1 as a potential inhibitory target of miR-152. ${ }^{59}$ Consequently, the downregulation of DNMT1 resulted in a decrease of cccDNA methylation, subsequently enhancing HBV replication. ${ }^{59}$

\section{miRNAs in HBV-related liver disease}

The clinical course of hepatitis B is dynamic and varies widely between patients from self-limited infection after acute hepatitis to chronic infection with a clinical presentation ranging from asymptomatic carrier state to severe expressions of disease, including active chronic hepatitis, liver cirrhosis, and HCC. ${ }^{60}$ Approximately $90-95 \%$ of immunocompetent individuals who acquire HBV infection in adulthood will clear the virus spontaneously, whereas the remaining (5-10\%) develop chronic hepatitis. The rate of chronicity is higher in perinatal and early childhood infections (over $90 \%$ and $30 \%$, respectively). ${ }^{60}$ Approximately $15-40 \%$ of HBV chronic carriers develop liver cirrhosis and HCC. ${ }^{61}$ Several host and viral mechanisms have been described to explain these diverse liver disease outcomes. ${ }^{62,63}$ There is accumulating evidence detailing the functions of miRNAs in HBV pathogenesis and identifying differentially expressed miRNAs and target genes in the different phases of liver disease. Some miRNAs have been shown to be altered by $\mathrm{HBV}$, especially liver-specific miRNAs, contributing to liver damage and HCC development.

\section{miRNAs in the chronicity of HBV infection}

It is widely believed that ineffective immune responses play an important role in HBV persistence and disease chronicity. ${ }^{63}$ MiRNAs have been found to function as regulators of the immune responses against HBV (Table 1 ). Su et al. demonstrated that miR-155 enhances the expression of several IFN-inducible antiviral genes against HBV through direct suppression of the expression of suppressor of cytokine signaling 1 (SOCS1), and subsequently enhancing the Janus kinase/ signal transducer and activator of transcription (JAK/STAT) signaling pathway. ${ }^{64}$ In contrast, miR-548 downregulates host antiviral responses by direct targeting IFN- $\lambda 1{ }^{65}$ Interestingly, endogenous miR-548 levels are reduced during HBV infection, which may be a host mechanism to defend against HBV. ${ }^{65}$ In turn, HBV infection may modulate the expression of many miRNAs involved in immune responses. By comparing the expression of 1,008 miRNAs between HepG2.2.15 cells and parenteral hepatoma cells HepG2, Jiang et al. observed a differential expression of miRNAs related to toll-like receptor (TLR) pathways. ${ }^{66}$ The expression of seven miRNAs (miR-200b-3p, miR-148a-3p, miR-145-5p, miR-146b-5p, miR-200c-3p, miR-455-3p and miR-455-5p) was upregulated by 5 -fold or greater in HepG2.2.15 cells compared to HepG2 cells, whereas the expression of eight miRNAs (from let-7 family) was downregulated by 5 -fold or greater in HepG2.2.15 cells compared to HepG2 cells. ${ }^{66}$ Most upregulated miRNAs have been demonstrated to modify the efficiency of TLR signaling. In addition, repression of the let-7 family of miRNAs relieved interleukin (IL)- 6 and IL-10 mRNAs from negative posttranscriptional control in the TLR4 signaling pathway. This induced an inhibition of immune responses directed against HBV. ${ }^{66}$ These findings indicated that alteration of miRNAs related to the TLR pathway during HBV infection could play an important role in the prevention of HBV elimination by host innate immunity. Furthermore, it has been reported that HBV infection promoted the transcriptional activity of miR-146a in HepG2.2.15 cells, which represses the production of type I interferon-induced antiviral factors, particularly STAT1, and results in interferon resistance. ${ }^{67}$ These observations revealed an important role for miR-146a in HBV immunopathogenesis. ${ }^{67}$ Another study analyzing the modified expression profiles of miRNAs in a stable HBV-expressing cell line revealed that upregulation of miR-181a might participate in $\mathrm{HBV}$ persistence through inhibition of the human leukocyte antigen A (HLA-A)-dependent HBV antigen presentation. ${ }^{68}$ Recently, Momeni et al. showed that expression of miR-1, miR-21, and miR-125a in peripheral blood immune cells was significantly increased in patients with chronic HBV infection compared to healthy controls and that ectopic expression of these miRNAs was responsible for 
Kitab B. et al: MicroRNAs and HBV infection

Table 1. Summary of miRNAs involved in the chronicity of HBV infection and liver cirrhosis

\begin{tabular}{|c|c|c|c|}
\hline miRNA & Expression $^{a}$ & $\begin{array}{l}\text { Target } \\
\text { gene }(s)\end{array}$ & Functions \\
\hline \multicolumn{4}{|c|}{ miRNAs involved in the chronicity of HBV infection } \\
\hline Let-7 family & Down & IL-6, IL-10, TLR4 & $\begin{array}{l}\text { Inhibits the expression of proinflammatory cytokine IL-6, } \\
\text { anti-inflammatory cytokine IL-10, and TLR4, thereby } \\
\text { influencing the control of immune responses and } \\
\text { inflammation }\end{array}$ \\
\hline miR-146a & Up & STAT1 & $\begin{array}{l}\text { Inhibits the production of type I interferon-induced } \\
\text { antiviral factors }\end{array}$ \\
\hline miR-155 & Up & SOSC1 & $\begin{array}{l}\text { Upregulates the expression of IFN-inducible antiviral } \\
\text { genes by suppressing SOSC1 and promoting JAK/STAT } \\
\text { signaling pathway }{ }^{64}\end{array}$ \\
\hline miR-181a & Up & HLA-A & $\begin{array}{l}\text { Downregulates the expression of HLA-A and inhibits the } \\
\text { HLA-A dependant HBV antigen presentation } 68\end{array}$ \\
\hline miR-548 & Down & IFN- $\lambda 1$ & $\begin{array}{l}\text { Inhibits expression of IFN- } \lambda 1 \text { and downregulates } \\
\text { immune responses }\end{array}$ \\
\hline $\begin{array}{l}\text { miR-145-5p, miR-146b-5p, } \\
\text { miR-148a, miR-200b-3p, } \\
-200 c-3 p, \text { miR-455 }\end{array}$ & Up & $\begin{array}{l}\text { SOCS7, IRAK1, } \\
\text { TRAF6, CaMKII, } \\
\text { MyD88, E2F1 }\end{array}$ & $\begin{array}{l}\text { Dowregulates the efficiency of TLR signaling pathways, } \\
\text { thereby affecting host innate defenses against } \mathrm{HBV}^{66}\end{array}$ \\
\hline $\begin{array}{l}\text { miR-1, miR-21, and } \\
\text { miR-125 }\end{array}$ & Up & Unknown & $\begin{array}{l}\text { Induces impaired immune responses against HBV and } \\
\text { facilitates HBV's evasion of the host immune system } 69\end{array}$ \\
\hline \multicolumn{4}{|c|}{ miRNAs involved in HBV-related cirrhosis } \\
\hline miR-19b & Down & TGF- $\beta$ & $\begin{array}{l}\text { Inhibits TGF- } \beta \text {-induced HSCs activation and prevents } \\
\text { fibrosis }^{72}\end{array}$ \\
\hline miR-29 & Down & $\begin{array}{l}\text { COL1A1, COL4A5, } \\
\text { COL5A3 }\end{array}$ & $\begin{array}{l}\text { Inhibits the expression of collagen in HSCs and prevents } \\
\text { fibrosis }^{74}\end{array}$ \\
\hline miR-33a & Up & Smad7 & $\begin{array}{l}\text { Stimulates TGF- } \beta \text {-induced HSCs activation and promotes } \\
\text { fibrosis }^{75}\end{array}$ \\
\hline $\mathrm{miR}-150$ & Down & $c-m y b$ & Inhibits collagen-I expression and HSCs activation ${ }^{73}$ \\
\hline miR-194 & Down & rac1 & Inhibits collagen-I expression and HSCs activation ${ }^{73}$ \\
\hline miR-615-3p & Up & Unknown & Promotes hypersplenism in HBV-related cirrhosis ${ }^{76}$ \\
\hline
\end{tabular}

${ }^{\mathrm{a}}$ Denotes endogenous expression in HBV-infected liver tissues or HBV-infected cell lines.

Down: downregulate; Up: upregulate; IL-6: interleukin 6; IL-10: interleukin 10; TLR4: toll-like receptor 4; STAT1: signal transducer and activator of transcription 1; SOSC1: suppressor of cytokine signaling 1 ; HLA-A: human leukocyte antigen A; IFN- $\lambda 1$ : Interferon $\lambda 1$; SOCS7: suppressor of cytokine signaling 7; IRAK1: interleukin-1 receptorassociated kinase 1; TRAF6: TNF receptor-associated factor 6; CaMKII: $\mathrm{Ca}^{2+} /$ calmodulin-dependent protein kinase II; MyD88: myeloid differentiation primary response gene 88; E2F1: E2F transcription factor 1; TGF- $\beta$ : transforming growth factor beta; COL1A1: collagen type 1 alpha 1; COL4A5: collagen type 4 alpha 5; Smad7: SMAD family member 7.

impaired immune responses in chronic HBV carriers. ${ }^{69}$ However, the role of these miRNAs in persistent HBV infection remains elusive and still awaits further investigation. ${ }^{69}$

\section{miRNAs in HBV-related liver fibrosis and cirrhosis}

Long term persistence of HBV infection can result in the development of liver inflammation and injury. HBV itself is considered to be a noncytopathic virus, and it is usually accepted that the process of destruction of HBV-infected cells is due to cell-mediated immune responses. ${ }^{63}$ Persistent inflammation has been shown to be the driving force leading to liver fibrosis, generated by an imbalance between production of extracellular matrix (ECM) by hepatic stellate cells (HSCs). ${ }^{70}$ This imbalance results in an excessive accumulation of ECM and fibrogenesis. ${ }^{70} \mathrm{~A}$ number of studies have focused on the role of miRNAs in HBV-associated liver fibrosis/cirrhosis and unveiled the miRNA expression profiles during this phase (Table 1). Guo et al. identified several miRNAs that were differentially expressed during HSCs activation and showed that different signaling pathways, already reported to take part in HSCs activation, were modulated by miRNAs. ${ }^{71}$ Lakner et al. reported that miR-19b inhibited HSC-mediated fibrogenesis by regulating transforming growth factor- $\beta$ (TGF- $\beta$ ) signaling in activated HSCs. ${ }^{72}$ In addition, Venugopal et al. showed that liver fibrosis may cause downregulation of miR-150 and miR-194 in HSCs and that their overexpression could repress HSCs activation. ${ }^{73}$ These miRNAs were observed to be downregulated in a feedback mechanism that occurs during the early phases of liver regeneration. ${ }^{73}$ Roderburg et al. applied a systematic approach to identify miRNAs involved in liver fibrosis using the well-established model of carbon tetrachloride $\left(\mathrm{CCl}_{4}\right)$ treatment for hepatic 
fibrogenesis in mice. ${ }^{74}$ They identified a panel of miRNAs that was specifically regulated in fibrotic-livers from mice treated with $\mathrm{CCl}_{4}$ compared to livers from control mice. Within those, the miR-29-family members (miR-29a/b/c) were significantly downregulated in $\mathrm{CCl}_{4}$-treated mice. ${ }^{.4}$ Interestingly, decreased expression of miR-29 in these animals was significantly correlated with the degree of liver fibrosis. The same study showed that miR-29b was downregulated during the activation of HSCs in a TGF- $\beta$ and lipopolysaccharide/nuclear factor kappa B (NF-кB)-dependent manner, whereas overexpression of miR-29b in murine HSCs resulted in downregulation of collagen expression. ${ }^{74}$ Another study reported that miR-33a levels in liver tissue from chronic HBV-infected patients increased significantly in a fibrosis progression manner. ${ }^{75}$ Interestingly, stimulation of HSCs with TGF- $\beta 1$ led to a critical increase of miR-33a. ${ }^{75}$

Hypersplenism is common in portal hypertension in patients with liver cirrhosis and results mostly from the increased phagocytosis and destruction of blood cells by splenic macrophages. To determine whether miRNA expression is altered in hypersplenism during HBV-related cirrhosis, Li et al. analyzed the entire miRNAome in macrophages from normal and portal hypertensive spleen samples. ${ }^{76}$ Compared to normal spleen samples, 99 miRNAs were found to be differentially expressed in splenic macrophages associated to portal hypertension, with a remarkable overexpression of miR-615-3p. ${ }^{76}$ These findings suggest that miRNAs could be novel regulators in hypersplenism in patients with HBVrelated cirrhosis.

\section{miRNAs in HBV-related HCC}

Chronic HBV infection remains a major etiological factor of HCC worldwide, increasing the risk for HCC development by 100 -fold compared to uninfected individuals. ${ }^{62}$ Many reports have shown that HCC develops through aberrant activation of various signaling pathways involved in cell proliferation, differentiation, and angiogenesis. ${ }^{77}$ However, the precise mechanisms underlying HBV related-HCC development remain unclear. ${ }^{77}$ It is now well-established that miRNAs play a critical role in HBV-associated hepatocarcinogenesis, as they can function as oncogenes or tumor suppressor genes depending on the cellular function of the target genes (Table 2). ${ }^{78} \mathrm{~A}$ study performed by Ura et al. showed that HBV infection induced specific sets of miRNAs during hepatocarcinogenesis, and their targets included genes involved in pathways related to cell proliferation, apoptosis, DNA damage, and signal transduction. ${ }^{79}$ Several research groups found that the liverspecific miR-122 was repressed in HBV-expressing HCC cell lines and in clinical tumor specimens. ${ }^{80-82}$ Suppression of miR-122 led to upregulation of its target N-myc downstream-regulated gene 3 (NDRG3), a tumor promoter, contributing to a malignant phenotype. ${ }^{80}$ In another study, low miR-122 levels promoted an overexpression of pituitary tumor-transforming gene 1 (PTTG1) binding factor (PBF), leading to increased transcriptional activity of PTTG and HCC cell growth and invasion. ${ }^{81}$ Furthermore, decreased miR-122 expression was linked to upregulation of cyclin $\mathrm{G} 1$, which promoted dephosphorylation of $\mathrm{Mdm}-2$, a repressor protein of p53, and led to HCC with unrestricted growth. ${ }^{82}$ A recent study showed that decreased miR-122 led to increased expression of its target UDP-N-acetyl- $\alpha$-D-galactosamine polypeptide $\mathrm{N}$-acetylgalacto-saminyltransferase-10 (GALNT10), conferring a malignant phenotype to HCC cells by modifying
EGFR O-glycosylation and activating the phosphatidylinositol 3-kinase (PI3K)/AKT signaling pathway. ${ }^{83}$ Given the functions of miR-122, investigators sought to explain its low expression in HBV-infected livers and found that miR-122 was downregulated by $\mathrm{HBx} .{ }^{83,84} \mathrm{HBx}$ is a multifunctional HBV-encoded protein that acts as a pleiotropic transactivator and modulates host gene expression by interacting with various cellular transcription factors and signaling pathways. ${ }^{77}$ Besides miR-122, several tumor suppressor-like miRNAs were shown to be suppressed by $\mathrm{HBx}$. Decreased expression of miR-101 by $\mathrm{HBx}$ resulted in overexpression of DNA methyltransferase $3 A$ (DNMT3A), promoting aberrant DNA hypermethylation of several tumor suppressor genes. ${ }^{85}$ In addition, under-expression of miR-101 contributed to increased levels of myeloid cell leukemia sequence 1 ( $\mathrm{Mcl}-1)$, an antiapoptotic member of the $\mathrm{Bcl}-2$ family. ${ }^{86}$ Antitumorigenic function of miR-148a was repressed by $\mathrm{HBx}$ via inhibition of $\mathrm{p} 53$-mediated activation of miR-148a. ${ }^{87}$ This led to increased expression of hematopoietic pre-B cell leukemia transcription factor-interacting protein (HPIP) and subsequent activation of the mammalian target of rapamycin (mTOR) pathway, which plays a critical role in cancer cell growth. ${ }^{87} \mathrm{HBx}$ also downregulated the let7 family of miRNAs, widely viewed as potential growth suppressor miRNAs in many cancers. ${ }^{88}$ Particularly important is the ability of the HBx protein and its RNA to act synergistically to downregulate another tumor suppressor pathway involving the miR-15a/miR-16-1cluster, which contributes to the activation of the proto-oncogene c-Myc. ${ }^{44}$ Epigenetic modulation of miRNA expression could be also an important mechanism underlying HBV-mediated hepatocarcinogenesis. For example, HBx induces epigenetic repression of two tumor-suppressors, miR-132 and miR-205, through DNA methylation of its promoters. ${ }^{89,90}$ Chen et al. found in HBVHCC tissues that increased miR-129-2 methylation was associated with subsequent miR-129-2 suppression. ${ }^{91}$ This suppression may be involved in HCC development through enhancing oncogenic SOX4 expression. ${ }^{91}$ Moreover, miR152 was shown to be targeted and downregulated by $\mathrm{HBx}$, causing an upregulation of DNMT1 activity and consequent DNA methylation of promoters of many tumor suppressor genes. ${ }^{59}$ Subsequent studies reported that miRNAs involved in the inhibition of cell proliferation (miR-15b, miR-22, miR-26a/b, miR-29c, miR-145, and miR199-a-3p) were downregulated in HBV-related HCC. ${ }^{92-98}$

Several oncogene-like miRNAs have been found to be upregulated in HBV-related HCC. Connolly et al. found that miR-17-92 cluster and miR-21 were significantly increased in human HBV-positive HCC tissues and woodchuck hepatitis virus-positive HCCs. ${ }^{99}$ They also demonstrated that miR17-92 and miR-21 contributed to a malignant phenotype by promoting cell proliferation and anchorage-independent growth. ${ }^{99}$ Oncogenic properties of the miR-17-92 cluster was shown to be related to a complex interaction network involving $\mathrm{HBx}$ protein and the transcription factors c-Myc and E2F1. Indeed, HBx transactivation of c-Myc led to induction of miR-17-92 expression by binding to its promoter. ${ }^{100}$ In turn, miR-17-92 inhibited E2F1 expression, causing defects in cell cycle control and HCC formation. ${ }^{100}$ Regarding miR-21, its expression was mediated by HBx-activation of the IL- 6 pathway followed by activation of STAT3, a positive regulator of the miR-21 promoter. ${ }^{101}$ MiR-21 enhanced cell proliferation by targeting tumor suppressor genes, including phosphatase and tensin homolog (PTEN) and programmed cell death protein-4 (PDCD4). ${ }^{102,103}$ Suppression of PTEN activity has been also 
Kitab B. et al: MicroRNAs and HBV infection

Table 2. Summary of oncogene- and tumor suppressor-like miRNAs involved in HBV-related HCC

\begin{tabular}{|c|c|c|c|}
\hline miRNA & Expression $^{a}$ & $\begin{array}{l}\text { Target } \\
\text { gene }(\mathrm{s})\end{array}$ & Functions \\
\hline \multicolumn{4}{|c|}{ Tumor suppressor-like miRNAs } \\
\hline Let-7 & Down & STAT3 & Inhibits cell proliferation ${ }^{88}$ \\
\hline miR-15a/miR-16-1 & Down & Bcl-2, Cyclin D1 & Inhibits cell proliferation ${ }^{44}$ \\
\hline miR-15b & Down & Fut2 & Inhibits cell proliferation ${ }^{92}$ \\
\hline miR-22 & Down & CDKN1A & Inhibits cell proliferation ${ }^{93}$ \\
\hline $\mathrm{miR}-26 \mathrm{a} / \mathrm{c}$ & Down & IL-6 & Inhibits cell proliferation ${ }^{94}$ \\
\hline miR-29c & Down & TNFAIP3 & Inhibits cell proliferation and promotes apoptosis ${ }^{95}$ \\
\hline miR-101 & Down & DNMT3A & Downregulates DNA hypermethylation ${ }^{85}$ \\
\hline miR-122 & Down & $\begin{array}{l}\text { NDRG3, } \\
\text { GALNT10 Cyclin } \\
\text { G1, PTTG1 }\end{array}$ & $\begin{array}{l}\text { Promotes cell apoptosis, inhibits cell proliferation and } \\
\text { invasion }{ }^{80-83}\end{array}$ \\
\hline miR-129-2 & Down & SOX4 & Reduces cell proliferation and clonogenicity ${ }^{91}$ \\
\hline miR-132 & Down & Akt & Inhibits cell proliferation ${ }^{90}$ \\
\hline miR-145 & Down & HDAC2, ADAM17 & Inhibits cell proliferation and cell invasion ${ }^{96,97}$ \\
\hline $\operatorname{miR}-148 a$ & Down & HPIP, MTOR & $\begin{array}{l}\text { Inhibits cell growth, epithelial-to-mesenchymal transition, } \\
\text { invasion, and metastasis }{ }^{87}\end{array}$ \\
\hline miR-152 & Down & DNMT1 & Reduces global DNA hypermethylation ${ }^{59}$ \\
\hline miR-199-a-3p & Down & mTOR, c-Met & $\begin{array}{l}\text { Blocks G1-S transition of the cell cycle, thereby inhibiting cell } \\
\text { growth, induces cell apoptosis, impairs invasion capability }{ }^{98}\end{array}$ \\
\hline miR-205 & Down & E2F1 & Inhibits cell proliferation ${ }^{89}$ \\
\hline \multicolumn{4}{|c|}{ Oncogene- like miRNAs } \\
\hline miR-17-92 & Up & $\mathrm{E} 2 \mathrm{~F} 1$ & Enhances cell growth and anchorage-independant growth 99,100 \\
\hline miR-18a & Up & ESR1 & Suppresses ER $\alpha$ synthesis and stimulates cell proliferation ${ }^{55}$ \\
\hline miR-21 & Up & PTEN, PDCD4 & $\begin{array}{l}\text { Promotes cell growth and anchorage-independant } \\
\text { growth }{ }^{102,103}\end{array}$ \\
\hline miR-27a & Up & Unknown & $\begin{array}{l}\text { Enhances cell proliferation, activates cell cycling, Promotes } \\
\text { migration and invasion }{ }^{110}\end{array}$ \\
\hline miR-29a & Up & PTEN & Promotes cell invasion/migration ${ }^{102}$ \\
\hline miR-143 & Up & FNDC3B & Promotes cell invasion and tumor metastasis ${ }^{105}$ \\
\hline miR-155 & Up & sox6 & Promotes cell growth ${ }^{111}$ \\
\hline miR-181 & Up & Fas, E2F5 & Inhibits cell apoptosis and promotes tumor cell growth ${ }^{108,109}$ \\
\hline miR-222 & Up & p27 (kip1), PTEN & Promotes cell growth and migration ${ }^{102}$ \\
\hline miR-224 & Up & SMAD4 & Promotes cell growth, migration and invasion 96,107 \\
\hline miR-602 & Up & RASSF1A & Inhibits cell apoptosis and promotes cell growth ${ }^{106}$ \\
\hline
\end{tabular}

${ }^{\mathrm{a}}$ Denotes endogenous expression in HBV-infected liver tissues or HBV-infected cell lines.

Down: downregulate; Up: upregulate; STAT1: signal transducer and activator of transcription 1; Fut2: fucosyltransferase 2; CDKN1A: cyclin-dependent kinase inhibitor 1A; IL-6: interleukin 6; TNFAIP3: tumor necrosis factor alpha-induced protein 3; DNMT3A: DNA methyltransferase 3A; NDRG3: N-myc downstream-regulated gene 3; GALNT10: UDP-N-acetyl- $\alpha$-D-galactosamine polypeptide N-acetylgalacto-saminyltransferase-10; SOX4: sex-determining region Y box 4; HDAC2: histone deacetylase 2; IGF1R: insulin-like growth factor 1 receptor; ADAM17: ADAM metallopeptidase domain 17; HPIP: pre-B cell leukemia transcription factor-interacting protein; mTOR: mechanistic target of rapamycin; DNMT1: DNA methyltransferase 1; E2F1: E2F transcription factor 1; ESR1: Estrogen receptor 1; PTEN: phosphatase and tensin homolog; PDCD4: programmed cell death 4; FNDC3B: fibronectin type III domain containing 3B; SOCS1: suppressor of cytokine signaling 1; SOX6: Sex-determining region Y box 6; E2F5: E2F transcription factor 5; SMAD4: SMAD family member 4; RASSF1A: Ras-associated domain family member 1A.

attributed to miR-29a and miR-222, which are upregulated by $\mathrm{HBx}$ to promote HCC cell growth and migration. ${ }^{102,104}$ Another relevant miR-222 target is the p27 (kip1) protein, a cell cycle inhibitor and tumor suppressor. ${ }^{102}$ In addition, $\mathrm{HBx}$ can induce the expression of nuclear factor-kappa B (NF-кB), an activator of miR-143 expression in HBV-related HCC. Overexpression of miR-143 inhibited the expression of fibronectin type III domain containing 3B (FNDC3B), a regulator of cell motility, thus stimulating HCC metastasis. ${ }^{105}$ Another HBx-upregulted miRNA was miR-602, which was shown to inhibit the tumor suppressive function of Rasassociated domain family member $1 \mathrm{~A}$ (RASSF1A). ${ }^{106}$ Notably, in chronic HBV hepatitis, liver cirrhosis to HCC, there is a progressive trend where an increase in miR-602 expression is correlated with a decrease in RASSF1A level, suggesting that miR-602 may promote HCC in HBV carriers at a very 
early stage. ${ }^{106}$ Similarly, a gradual increase in the expression of miR-224 was observed from premalignant dysplastic nodules to HCC. ${ }^{96}$ High miR-224 levels were found to be correlated with downregulation of its target gene Smad4, a tumor suppressor in liver tumorigenesis. ${ }^{107}$ Epigenetic modifications in miRNA promoters represent another mechanism whereby $\mathrm{HBx}$ affects onco-miRNA expression. MiR-181a was identified as an epigentic target of $\mathrm{HBx}$, which upregulates its expression in both HCC cell lines and specimens. ${ }^{108}$ MiR-181a promoted cell growth in vitro and tumor formation in vivo by targeting the transcription factor E2F5, a key regulator of cell growth. ${ }^{108}$ Another study reported that miR-181a decreased apoptosis by inhibiting expression of the TNF receptor superfamily member 6 (Fas), an important inducer of apoptosis. ${ }^{109}$ The ability to promote cell growth was also demonstrated for miR-27a, which was upregulated in both HBV-positive HCC tissues and hepatoma cell lines. ${ }^{110}$ MiR-27a may also enhance migration and invasion of HCC cells. ${ }^{110}$ Moreover, a serial cohort study performed by Liu et al. reported an important miRNA-mediated regulatory mechanism that may promote malignant transformation in hepatocytes by affecting the estrogen receptor $\alpha(E R \alpha)$ signaling pathways. ${ }^{55}$ Estrogen plays an important role in protecting against the development of HBV-related HCC, which partially explains the sex disparity characteristic in HCC. However, it has been found that miR-18a directly suppress ER $\alpha$ mRNA translation, thereby blocking the tumor-protective activity of estrogens in women. ${ }^{55}$ In correlation to these data, increased levels of miR-18a in female HCC tissues correlated with reduced ER $\alpha$ expression. Similar results were also found in cell lines where overexpression of miR-18a not only decreased ER $\alpha$ levels but also stimulated cell proliferation. ${ }^{55}$ Additionally, aberrant expression of miRNAs involved in the modulation of immune responses during $\mathrm{HBV}$ infection plays a significant role in the development of immune-mediated liver damage, thereby promoting HCC. MiR-155 is well-known for its role as an enhancer of antiviral immunity against HBV. ${ }^{64}$ However, Wang et al. showed that overexpression of miR-155 can lead to prolonged exposure to inflammatory responses, which contribute to progressive liver damage and $\mathrm{HCC}^{46}$ Another study reported that miR-155 may promote $\mathrm{HCC}$ by targeting sexdetermining region $Y$ box 6 (SOX6), a transcriptional regulator that inhibits cell growth by stimulating the p21 growth regulator in a p53-dependent manner. ${ }^{111}$

\section{miRNAs as diagnostic biomarkers of HBV-related liver disease}

One of the major challenges in HBV research is identifying effective noninvasive biomarkers of HBV-related liver disease. Such markers can allow for rapid intervention and improved patient outcomes after curative treatment. The discovery of cell-free circulating miRNAs, which were able to mirror pathophysiological conditions in human bodily fluids, has opened new avenues for application of miRNAs as biomarkers for liver disease. ${ }^{112}$ Moreover, their accessibility and high stability in the circulatory system make them ideal biomarkers for the diagnosis of disease at an early, presymptomatic stage. ${ }^{112}$ Several studies have analyzed miRNA profiles in sera from HBV carriers in order to identify useful biomarkers (Table 3). Zhang et al. selected miRNA biomarkers from patients with HBV infection, patients with skeletal muscle disease, and healthy subjects. ${ }^{113}$ They showed that increased serum miR-122 levels correlated with histopathologic alterations and appeared earlier compared with alanine aminotransferase (ALT) levels, which remained within the reference intervals. ${ }^{113}$ Also, increased serum miRNA-122 levels were more specific for liver injury than for other organ damage. ${ }^{113}$ Other studies showed that serum miR-122 may allow for discrimination of HCC patients from healthy subjects but was not useful for distinguishing HCC cases from HBV carriers. ${ }^{114,115}$ Serum miR-223 together with miR-125b-5p have been reported as promising biomarkers of very early HBV-positive HCC, even in advanced stages of liver disease due to chronic hepatitis B. ${ }^{116}$ Other miRNAs have been suggested to have great diagnostic value. Serum miR124 levels have been found to be significantly higher in HBVinfected patients with considerable liver necroinflammation than HBV-patients without or with mild necroinflammation. ${ }^{117}$ In addition, after antiviral therapy, serum miR-124 levels considerably declined, in association with histological improvement. ${ }^{117}$ Huang et al. showed that serum miR-29 levels were significantly higher in patients with minimal fibrosis than patients with liver cirrhosis (LC), suggesting that patients with minimal liver inflammation tended to express higher serum miR-29 levels than those with advanced inflammation. ${ }^{118}$ MiR-18a has been shown to have a significant diagnostic value for HBV-related HCC screening. ${ }^{119}$ MiR-18a yielded an area under the curve (AUC) of receiver operating characteristic (ROC) of 0.88 (specificity: $75 \%$; sensitivity: $86 \%$ ) in discriminating HBV-related HCC from healthy controls, and an AUC of ROC of 0.78 (specificity: $70 \%$; sensitivity: $77 \%$ ) in discriminating HBV-related HCC from chronic hepatitis B or HBVrelated LC. ${ }^{119} \mathrm{~A}$ recent study by Xie et al. reported that miR-101 can serve as a potentiel biomarker to differentiate HBV-HCC from HBV-LC. ${ }^{120}$ Serum miR-101 is downregulated in HBV-HCC patients compared with HBV-LC patients. ROC analysis of serum miR-101 yielded an AUC of 0.98 (sensitivity: 96\%; specificity: 90\%) when differentiating between HBV-HCC and HBV-LC. ${ }^{120}$ Interestingly, serum miR-101 was superior to alpha-fetoprotein (AFP) for diagnosing HBV-HCC derived from HBV-LC. Combining serum miR-101 with AFP had no advantage over serum miR-101 alone for detecting HBV-HCC derived from HBV-LC. ${ }^{120}$ The frequent finding of dysregulated miRNAs in HBV-related HCC has sparked several research groups to conduct searches to identify a panel of serum miRNAs that may be potentially useful in the diagnosis of HBV-related HCC. Zou et al. identified a serum miRNA panel (miR-122, miR-192, miR-21, miR-223, miR-26a, miR-27a, and miR-801) that provided a high diagnostic accuracy of HBV-related HCC and was able to successfully distinguish HCC patients from chronic hepatitis and liver cirrhosis patients and healthy cases. ${ }^{121}$ Furthermore, Li et al. successfully identified $13 \mathrm{HBV}$-specific miRNAs that can clearly discriminate not only HBV cases from healthy controls and HCV cases but also HBV-positive HCC cases from controls and HBV cases. ${ }^{122}$ Six of these miRNAs (miR-1, miR-25, miR-92a, miR206, miR-375, and let-7f) were significantly elevated in HCC cases, and two miRNAs, miR-375 and miR-92a, were previously identified as HBV-specific. In addition, the use of three of these miRNAs (let-7f, miR-25, and miR-375) as biomarkers, clearly separated HCC cases from controls, and miR-375 alone had an AUC of ROC of 0.96 (specificity: $96 \%$; sensitivity: $100 \%$ ) for HCC diagnosis. ${ }^{122}$

Interestingly, a study by Novellino et al. provided evidence that HBV subviral particles carry hepatocellular miRNAs to be released from $\mathrm{HBV}$-infected cells into the blood. ${ }^{123}$ The experimental strategy consisted on the isolation of HBV subviral 
Kitab B. et al: MicroRNAs and HBV infection

Table 3. Clinical relevance of miRNAs in the diagnosis of HBV-related liver disease

\begin{tabular}{|c|c|c|}
\hline miRNA & Expression & Clinical relevance \\
\hline miR-18a & $U p^{a}$ & $\begin{array}{l}\text { Biomarker to detect HCC patients from healthy subjects and patients with } \\
\text { chronic hepatitis or liver cirrhosis }{ }^{119}\end{array}$ \\
\hline miR-29 & Down ${ }^{\mathrm{b}}$ & $\begin{array}{l}\text { Biomarker of severe liver necroinflammation and cirrhosis }{ }^{118} \\
\text { Negative correlation with the severity of liver injuries }\end{array}$ \\
\hline miR-101 & $U p^{a}$ & $\begin{array}{l}\text { Biomarker to differentiate HBV-HCC from HBV-liver cirrosis }{ }^{120} \\
\text { Screening HCC patients from healthy subjects }{ }^{120} \\
\text { Increased serum miR-101 levels correlated with tumor size }{ }^{120}\end{array}$ \\
\hline miR-122 & $U p^{a, b}$ & $\begin{array}{l}\text { Biomarker of severe liver necroinflammation }{ }^{113,114} \\
\text { Positive correlation with the severity of liver injuries }{ }^{113,114} \\
\text { Potential biomarker for detection of HCC in healthy subjects }{ }^{115}\end{array}$ \\
\hline miR-124 & $U p^{b}$ & $\begin{array}{l}\text { Biomarker for considerable liver necroinflammation in patients with chronic } \\
\text { hepatitis } B \text {, particularly in those with normal or mildly increased ALT level }{ }^{117} \\
\text { Declined serum miRNA-124 after antiviral treatment was a promising biomarker } \\
\text { of histological remission }{ }^{117}\end{array}$ \\
\hline $\begin{array}{l}\text { miR-125b-5p and } \\
\text { miR-223-3p }\end{array}$ & Up $^{a}$ Down ${ }^{a}$ & $\begin{array}{l}\text { Biomarkers of HBV-positive HCC in very early, even at chronic hepatitis B stage } \\
\text { of liver disease }\end{array}$ \\
\hline $\begin{array}{l}\text { miR-122, miR-192, miR-21, } \\
\text { miR-223, miR-26a, } \\
\text { miR-27a, and miR-801 }\end{array}$ & $U p^{a}$ & $\begin{array}{l}\text { Biomarkers to detect HCC patients from those with chronic hepatitis, liver } \\
\text { cirrhosis and healthy cases }{ }^{121}\end{array}$ \\
\hline let-7f, miR-25, and miR-375 & $U p^{a}$ & $\begin{array}{l}\text { Biomarkers for HBV infection and HBV-related } \mathrm{HCC}^{122} \\
\text { High sensitivity to detect HBV-positive cases from HCV-positive cases and } \\
\text { healthy subjects }{ }^{122} \\
\text { High sensitivity to detect HBV-positive HCC cases from those with chronic } \\
\text { hepatitis B and healthy cases }{ }^{122}\end{array}$ \\
\hline
\end{tabular}

a Denotes serum miRNA level in patients with HBV-related HCC compared to patients with chronic hepatitis, liver cirrhosis or healthy controls.

${ }^{b}$ Denotes serum miRNA level in patients with moderate-to-severe liver necroinfiammation compared to those with no or mild necroinfiammation.

Down: downregulate; Up: upregulate

particles from sera of $11 \mathrm{HBV}$-infected patients using selective immunoprecipitation and screening of human miRNAs in each sample by real-time quantitative polymerase chain reaction (PCR). ${ }^{123}$ Thirty-nine miRNAs were identified to be significantly associated with the immunoprecipitated HBV subviral particles. Most of them were liver-specific (miR-27a, miR-30b, miR-122, miR-126, and miR-145) and belonged to the previously described repertoires of miRNAs differentially expressed in liver development, disease, fibrosis, and/or regeneration (miR-122, miR- 27a, miR-29a, miR-30a, miR30b, miR-126, miR-145, and miR-223). ${ }^{123}$ These findings suggested that HBV subviral particles provide a new noninvasive tool for liver-specific miRNA profiling, allowing for the study of dynamic changes in hepatocellular miRNA expression during HBV infection in serum samples.

\section{miRNA-based therapy for HBV-related liver disease}

The goal of hepatitis B treatment is to improve patients' quality of life and increase survival by preventing progression to liver cirrhosis and $\mathrm{HCC}^{4}$ Achieving this goal is done by sustained suppression of HBV replication, which is accompanied by reduced histological activity of chronic hepatitis, leading to decreased risk of disease progression. ${ }^{4}$ The current anti-HBV drugs, including IFN $\alpha$ and nucleos(t)ide analogues, may effectively suppress HBV replication and induce remission of liver disease. However, the side effects of IFN $\alpha$ and the emergence of viral resistance during long-term therapy with nucleos(t)ide analogues make these therapeutic approaches far from satisfactory. ${ }^{4}$ Furthermore, after treatment withdrawal, most patients do not manifest durable control of infection and viral reactivation occurs. ${ }^{4}$ The persistence of intrahepatic cccDNA, the template of viral transcription, is the main cause of viral reactivation, given that IFN $\alpha$ and nucleos(t)ide analogues are unable to eradicate cccDNA from the liver. ${ }^{4,56}$ Therefore, developing novel antivirals that improve viral clearance with minimal side effects and potently eradicate cccDNA is required for a cure or durable control of HBV infection.

The close relationship between miRNA expression and HBV-related liver disease has fueled an interest in exploiting miRNAs as therapeutic targets for the control and eradication of hepatitis B. Ely et al. have taken advantage of the natural RNA polymerase II-mediated transcriptional control of cellular miRNAs and designed RNA polymerase II promoter cassettes that transcribe anti-HBV primary miRNA (pri-miR)-122 and pri-miR-31 shuttles. ${ }^{124}$ MiR-122 and miR-31 backbones were selected because these sequences were predicted to favor intrahepatic processing of adapted anti-HBV shuttles. In addition, miR-122 is liver-specific and pri-miR-31 is efficiently processed by Drosha. They found that anti-HBV miRs generated an intended guide strand of $\sim 21 \mathrm{nt}$, which confirmed that these sequences functioned as pri-miR mimics and were processed in a manner similar to those of natural pri-miRs. ${ }^{124}$ Studies on effects of these anti-HBV miRs shuttles in vitro and in vivo demonstrated a potent silencing of markers of HBV replication with no evidence of toxicity or disruption of independent miR-mediated silencing. ${ }^{124}$ In a 
similar strategy, Chattopadhyay et al. developed linear expression cassettes that produced anti-HBV miRs shuttles. Silencing of HBV markers of replication was efficient (>75\%) in cultured cells and in vivo. ${ }^{125}$ Furthermore, a knock down of approximately $95 \%$ HBV replication was attained in a hydrodynamic infection model. ${ }^{125}$ Together, these findings suggest that employing miRs shuttles is potentially valuable for treating HBV infection. However, besides antiviral efficiency, improvement of liver expression and efficient delivery of miRs shuttles is potentially important to limit nonspecific effects. In this context, Mowa et al. investigated the utility of the liverspecific murine transthyretin receptor (MTTR) Pol II promoter for expression of anti-HBV pri-miRs by incorporating MTTR promoter into the helper dependent adenoviral vectors (HDAds) carrying pri-miR expression cassettes. ${ }^{126}$ The results revealed that MTTR-expressed pri-miRs induced a knockdown of up to $94 \%$ of HBV replication in HBV transgenic mouse model and did not result in hepatotoxicity. ${ }^{126}$ Notably, HD Ads affected efficient delivery of pri-miRs targeting HBV. Another important property of HD Ads is their capacity for accommodating large transgene sequences. ${ }^{126}$ Therefore, as well as miRs activating cassettes, other antiHBV elements may be incorporated into HD Ads to augment their therapeutic efficacy. Recent advances regarding the role of engineered gene-modifying enzymes such as transcription activator like effecter nucleases (TALENs) and zinc finger nucleases in cleavage of HBV ccCDNA have been impressive. ${ }^{127}$ These enzymes may be used in combination with HBV-targeting miRNAs activators to efficiently control or eradicate HBV infection. Another improvement in miRNA therapy is the use of lentiviral miRNA-based system (LVshHBS) expressing siRNAs targeting the HBsAg gene of HBV genome. ${ }^{128}$ LVshHBS significantly inhibited the HBsAg mRNA and protein levels in HepG2.2.15 cells, while HBsAg secretion into the culture supernatant was decreased by $70 \% .{ }^{128}$ Also, in LVshHBS-transduced HepG2.2.15 cells, expression of genes involved in cell cycle and oncogenesis was downregulated, indicating that LVshHBS not only inhibited HBV replication but also inhibited the growth of HCC. ${ }^{128}$ Although these experimental studies have confirmed the capacity of miRNAbased antivirals to treat hepatitis $B$, adequate evaluation of their efficacy is required and further research is needed to determine their impact alone or in combination to other antiviral elements on HBV eradication.

\section{Conclusions}

In summary, this review adds to a growing body of evidence concerning the complex interactions between host-encoded miRNAs and HBV. MiRNAs are considered as important cellular regulatory molecules that profoundly modulate HBV genes expression. Their functions are mainly mediated by interacting with HBV transcripts, cellular genes, and signaling pathways that have a critical role in viral replication and pathogenesis. In turn, HBV modulates the expression of miRNAs in HBV-infected cells and promotes the development of liver disease and HCC. It is true that these findings regarding HBV-miRNA interactions have contributed to important progress in understanding HBV pathogenesis. However, further research is needed to clarify the mechanisms by which host miRNA expression is altered during HBV infection and the role of miRNA alterations in cellular functions and liver disease processes. Regarding clinical applications, altered expression profiles of cell-free circulating miRNAs in serum/plasma between the different stages of HBV-mediated liver disease have opened new insights into the utility of miRNAs as noninvasive biomarkers. This is particularly true in the diagnosis of liver inflammation and HCC at an early stage and to predict the risk of disease progression. Although a large number of miRNAs have been identified as promising biomarkers, it is only practical to use the most sensitive and specific ones with complementary functions in clinical settings. Additionally, it is very important to elucidate the mechanisms of how cell-free circulating miRNAs are changed in the serum/plasma of HBV-infected patients and whether these circulating miRNAs influence HBV pathogenesis. Understanding the role of altered miRNA expression either in serum or liver provides a strong basis for targeting miRNAs in the treatment of hepatitis $B$, and it is likely that miRNA-based therapies will be part of the therapeutic armamentarium against $\mathrm{HBV}$ in the future.

\section{Conflict of interest}

None

\section{Author contributions}

Review design (BK, SB), collection of data (BK), writing the manuscript ( $B K, S B)$, revising the article for important intellectual content (SB, HSA, SE).

\section{References}

[1] Alter $\mathrm{HJ}$. To have $\mathrm{B}$ or not to have $\mathrm{B}$ : vaccine and the potential eradication of hepatitis B. J Hepatol 2012;57:715-717. doi: 10.1016/j.jhep.2012. 06.032.

[2] Liaw YF, Chu CM. Hepatitis B virus infection. Lancet 2009;373:582-592. doi: 10.1016/S0140-6736(09)60207-5.

[3] http://www.who.int/mediacentre/factsheets/fs204/en, accessed July 2014.

[4] European Association For The Study of The Liver. EASL clinical practice guidelines: Management of chronic hepatitis B virus infection. J Hepatol 2012;57:167-185. doi: 10.1016/j.jhep.2012.02.010.

[5] Zoulim F, Locarnini S. Hepatitis B virus resistance to nucleos(t)ide analogues. Gastroenterology 2009;137:1593-1608.e1-e2. doi: 10.1053/j. gastro.2009.08.063.

[6] Dandri M, Locarnini S. New insight in the pathobiology of hepatitis B virus infection. Gut 2012;61:i6-i17. doi: 10.1136/gutjnl-2012-302056.

[7] Bertoletti A, Maini MK, Ferrari C. The host-pathogen interaction during HBV infection: immunological controversies. Antivir Ther 2010;15:15-24. doi: 10.3851/IMP1620.

[8] Bartel DP. MicroRNAs: target recognition and regulatory functions. Cell 2009;136:215-233. doi: 10.1016/j.cell.2009.01.002.

[9] Qureshi A, Thakur N, Monga I, Thakur A, Kumar M. VIRmiRNA: a comprehensive resource for experimentally validated viral miRNAs and their targets. Database (Oxford) 2014;2014. doi: 10.1093/database/bau103.

[10] Axtell MJ, Westholm JO, Lai EC. Vive la difference: biogenesis and evolution of microRNAs in plants and animals. Genome Biol 2011;12:221. doi: 10. 1186/gb-2011-12-4-221.

[11] Lee RC, Feinbaum RL, Ambros V. The C. elegans heterochronic gene lin-4 encodes small RNAs with antisense complementarity to lin-14. Cell 1993; 75:843-854. doi: 10.1016/0092-8674(93)90529-Y.

[12] Saini HK, Griffiths-Jones S, Enright AJ. Genomic analysis of human microRNA transcripts. Proc Natl Acad Sci USA 2007;104:17719-17724. doi: 10. 1073/pnas.0703890104.

[13] Rodriguez A, Griffiths-Jones S, Ashurst JL, Bradley A. Identification of mammalian microRNA host genes and transcription units. Genome Res 2004;14: 1902-1910. doi: 10.1101/gr.2722704.

[14] Lee Y, Kim M, Han J, Yeom KH, Lee S, Baek SH, et al. MicroRNA genes are transcribed by RNA polymerase II. EMBO J 2004;23:4051-4060. doi: 10. 1038/sj.emboj.7600385.

[15] Denli AM, Tops BB, Plasterk RH, Ketting RF, Hannon GJ. Processing of primary microRNAs by the Microprocessor complex. Nature 2004;432:231235. doi: $10.1038 /$ nature03049. 
[16] Yi R, Qin Y, Macara IG, Cullen BR. Exportin-5 mediates the nuclear export of pre-microRNAs and short hairpin RNAs. Genes Dev 2003;17:3011-3016. doi: $10.1101 /$ gad.1158803.

[17] Lund E, Guttinger S, Calado A, Dahlberg JE, Kutay U. Nuclear export of microRNA precursors. Science 2004;303:95-98.

[18] Gregory RI, Chendrimada TP, Cooch N, Shiekhattar R. Human RISC couples microRNA biogenesis and posttranscriptional gene silencing. Cell 2005; 123:631-640. doi: 10.1016/j.cell.2005.10.022.

[19] Cheloufi S, Dos Santos CO, Chong MM, Hannon G]. A dicer-independent miRNA biogenesis pathway that requires Ago catalysis. Nature 2010;465: 584-589. doi: 10.1038/nature09092.

[20] Chendrimada TP, Gregory RI, Kumaraswamy E, Norman J, Cooch N, Nishikura $\mathrm{K}$, et al. TRBP recruits the Dicer complex to Ago2 for microRNA processing and gene silencing. Nature 2005;436:740-744. doi:10. 1038/nature03868.

[21] Djuranovic S, Nahvi A, Green R. miRNA-mediated gene silencing by translational repression followed by mRNA deadenylation and decay. Science 2012;336:237-240. doi: 10.1126/science.1215691.

[22] Guo H, Ingolia NT, Weissman JS, Bartel DP. Mammalian microRNAs predominantly act to decrease target mRNA levels. Nature 2010;466:835-840. doi: $10.1038 /$ nature09267.

[23] Liu J, Rivas FV, Wohlschlegel J, Yates JR 3rd, Parker R, Hannon G]. A role for the P-body component GW182 in microRNA function. Nat Cell Biol 2005;7: 1261-1266. doi: 10.1038/ncb1333.

[24] Lewis $B P$, Burge $C B$, Bartel DP. Conserved seed pairing, often flanked by adenosines, indicates that thousands of human genes are microRNA targets. Cell 2005;120:15-20. doi: 10.1016/j.cell.2004.12.035.

[25] Ebert MS, Sharp PA. Roles for microRNAs in conferring robustness to biological processes. Cell 2012;149:515-524. doi: 10.1016/j.cell.2012. 04.005.

[26] Mendell JT, Olson EN. MicroRNAs in stress signaling and human disease. Cell 2012;148:1172-1187. doi: 10.1016/j.cell.2012.02.005.

[27] Calin GA, Croce CM. MicroRNA signatures in human cancers. Nat Rev Cancer 2006;6:857-866. doi: 10.1038/nrc1997.

[28] Skalsky RL, Cullen BR. Viruses, microRNAs, and host interactions. Annu Rev Microbiol 2010;64:123-141. doi: 10.1146/annurev.micro.112408.134243.

[29] Sullivan CS. New roles for large and small viral RNAs in evading host defences. Nat Rev Genet 2008;9:503-507. doi: 10.1038/nrg2349.

[30] Grundhoff A, Sullivan CS. Virus-encoded microRNAs. Virology 2011;411: 325-343. doi: 10.1016/j.virol.2011.01.002.

[31] Seeger C, Mason WS. Hepatitis B virus biology. Microbiol Mol Biol Rev 2000; 64:51-68. doi: 10.1128/MMBR.64.1.51-68.2000.

[32] Beck J, Nassal M. Hepatitis B virus replication. World J Gastroenterol 2007; 13:48-64. doi: 10.3748/wjg.v13.i1.48.

[33] Quasdorff M, Protzer U. Control of hepatitis B virus at the level of transcription. J Viral Hepat 2010;17:527-536. doi: 10.1111/j.1365-2893. 2010.01315.x.

[34] Bar-Yishay I, Shaul Y, Shlomai A. Hepatocyte metabolic signalling pathways and regulation of hepatitis B virus expression. Liver Int 2011;31:282-290. doi: $10.1111 / j .1478-3231.2010 .02423 . x$.

[35] Jin WB, Wu FL, Kong D, Guo AG. HBV-encoded microRNA candidate and its target. Comput Biol Chem 2007;31:124-126. doi:10.1016/j.compbiolchem.2007.01.005.

[36] Zhang GL, Li YX, Zheng SQ, Liu M, Li X, Tang H. Suppression of hepatitis B virus replication by microRNA-199a-3p and microRNA-210. Antiviral Res 2010;88:169-175. doi: 10.1016/j.antiviral.2010.08.008.

[37] Potenza N, Papa U, Mosca N, Zerbini F, Nobile V, Russo A. Human microRNA hsa-miR-125a-5p interferes with expression of hepatitis B virus surface antigen. Nucleic Acids Res 2011;39:5157-5163. doi: 10.1093/nar/gkr067.

[38] Mosca N, Castiello F, Coppola N, Trotta MC, Sagnelli C, Pisaturo M, et al. Functional interplay between hepatitis $B$ virus $X$ protein and human miR125a in HBV infection. Biochem Biophys Res Commun 2014;449:141-145. doi: $10.1016 /$ j.bbrc. 2014.05.009.

[39] Chen Y, Shen A, Rider PJ, Yu Y, Wu K, Mu Y, et al. A liver-specific microRNA binds to a highly conserved RNA sequence of hepatitis $B$ virus and negatively regulates viral gene expression and replication. FASEB J 2011;25: 4511-4521. doi:10.1096/fj.11-187781.

[40] Qiu L, Fan H, Jin W, Zhao B, Wang $Y$, Ju $Y$, et al. miR-122-induced downregulation of HO-1 negatively affects miR-122-mediated suppression of HBV. Biochem Biophys Res Commun 2010;398:771-777. doi: 10.1016/j. bbrc.2010.07.021.

[41] Wang S, Qiu L, Yan X, Jin W, Wang Y, Chen L, et al. Loss of microRNA 122 expression in patients with hepatitis $B$ enhances hepatitis $B$ virus replication through cyclin G(1) -modulated P53 activity. Hepatology 2012;55:730741. doi: $10.1002 /$ hep. 24809.

[42] Ori A, Zauberman A, Doitsh G, Paran N, Oren M, Shaul Y. p53 binds and represses the HBV enhancer: an adjacent enhancer element can reverse the transcription effect of p53. EMBO J 1998;17:544-553. doi: 10.1093/ emboj/17.2.544.
[43] Kohno T, Tsuge M, Murakami E, Hiraga N, Abe H, Miki D, et al. Human microRNA hsa-miR-1231 suppresses hepatitis $B$ virus replication by targeting core mRNA. J Viral Hepat 2014;21:e89-e97. doi: 10.1111/jvh.12240.

[44] Wang $Y$, Jiang L, Ji X, Yang B, Zhang Y, Fu XD. Hepatitis B viral RNA directly mediates down-regulation of the tumor suppressor microRNA miR15a/miR-16-1 in hepatocytes. J Biol Chem 2013;288:18484-18493. doi: 10.1074/jbc.M113.458158.

[45] Hu W, Wang $X$, Ding $X$, Li Y, Zhang $X$, Xie $P$, et al. MicroRNA-141 represses HBV replication by targeting PPARA. PLoS One 2012;7:e34165. doi: 10. 1371/journal.pone.0034165.

[46] Wang B, Majumder S, Nuovo G, Kutay H, Volinia S, Patel T, et al. Role of microRNA-155 at early stages of hepatocarcinogenesis induced by cholinedeficient and amino acid-defined diet in C57BL/6 mice. Hepatology 2009; 50:1152-1161. doi: 10.1002/hep.23100.

[47] Lopez-Cabrera M, Letovsky J, Hu KQ, Siddiqui A. Transcriptional factor C/EBP binds to and transactivates the enhancer element II of the hepatitis $B$ virus. Virology 1991;183:825-829. doi: 10.1016/0042-6822(91)91019-D.

[48] Zhao F, Xu G, Zhou Y, Wang L, Xie J, Ren S, et al. MicroRNA-26b Inhibits Hepatitis B Virus Transcription and Replication by Targeting the Host Factor CHORDC1 Protein. J Biol Chem 2014;289:35029-35041. doi: 10.1074/jbc. M114.589978.

[49] Zhang $Z$, Chen J, He $Y$, Zhan $X$, Zhao R, Huang $Y$, et al. miR-125b inhibits hepatitis $B$ virus expression in vitro through targeting of the SCNN1A gene. Arch Virol 2014;159:3335-3343. doi: 10.1007/s00705-014-2208-y.

[50] Melegari M, Scaglioni PP, Wands JR. Cloning and characterization of a novel hepatitis $B$ virus $x$ binding protein that inhibits viral replication. J Virol 1998; 72:1737-1743.

[51] Jin J, Tang S, Xia L, Du R, Xie H, Song J, et al. MicroRNA-501 promotes HBV replication by targeting HBXIP. Biochem Biophys Res Commun 2013;430: 1228-1233. doi: 10.1016/j.bbrc.2012.12.071.

[52] Guo H, Liu H, Mitchelson K, Rao H, Luo M, Xie L, et al. MicroRNAs-372/373 promote the expression of hepatitis $B$ virus through the targeting of nuclear factor I/B. Hepatology 2011;54:808-819. doi: 10.1002/hep.24441.

[53] Dai $X$, Zhang W, Zhang $H$, Sun S, Yu H, Guo Y, et al. Modulation of HBV replication by microRNA-15b through targeting hepatocyte nuclear factor 1alpha. Nucleic Acids Res 2014;42:6578-6590. doi: 10.1093/nar/gku260.

[54] Wang SH, Yeh SH, Lin WH, Yeh KH, Yuan Q, Xia NS, et al. Estrogen receptor alpha represses transcription of HBV genes via interaction with hepatocyte nuclear factor 4alpha. Gastroenterology 2012;142:989-998. e4. doi: 10. 1053/j.gastro.2011.12.045

[55] Liu WH, Yeh SH, Lu CC, Yu SL, Chen HY, Lin CY, et al. MicroRNA-18a prevents estrogen receptor-alpha expression, promoting proliferation of hepatocellular carcinoma cells. Gastroenterology 2009;136:683-693. doi: 10. 1053/j.gastro.2008.10.029.

[56] Levrero M, Pollicino T, Petersen J, Belloni L, Raimondo G, Dandri M. Control of cccDNA function in hepatitis B virus infection. J Hepatol 2009;51:581592. doi: 10.1016/j.jhep.2009.05.022

[57] Zhang X, Zhang E, Ma Z, Pei R, Jiang M, Schlaak JF, et al. Modulation of hepatitis $B$ virus replication and hepatocyte differentiation by MicroRNA-1. Hepatology 2011;53:1476-1485. doi: 10.1002/hep.24195.

[58] Ramiere C, Scholtes C, Diaz O, Icard V, Perrin-Cocon L, Trabaud MA, et al. Transactivation of the hepatitis $B$ virus core promoter by the nuclear receptor FXRalpha. J Virol 2008;82:10832-10840. doi: 10.1128/JVI.00883-08.

[59] Huang J, Wang Y, Guo Y, Sun S. Down-regulated microRNA-152 induces aberrant DNA methylation in hepatitis B virus-related hepatocellular carcinoma by targeting DNA methyltransferase 1 . Hepatology 2010;52: 60-70. doi: 10.1002/hep.23660.

[60] Fattovich G, Bortolotti F, Donato F. Natural history of chronic hepatitis B: special emphasis on disease progression and prognostic factors. J Hepatol 2008;48:335-352. doi: 10.1016/j.jhep.2007.11.011.

[61] Lok AS. Chronic hepatitis B. N Engl ] Med 2002;346:1682-1683. doi: 10. 1056/NEJM200205303462202.

[62] Kao JH, Chen PJ, Chen DS. Recent advances in the research of hepatitis B virus-related hepatocellular carcinoma: epidemiologic and molecular biological aspects. Adv Cancer Res 2010;108:21-72. doi: 10.1016/B978-012-380888-2.00002-9.

[63] Chisari FV, Isogawa M, Wieland SF. Pathogenesis of hepatitis B virus infection. Pathol Biol (Paris) 2010;58:258-266. doi: 10.1016/j.patbio. 2009.11.001.

[64] Su C, Hou Z, Zhang C, Tian Z, Zhang J. Ectopic expression of microRNA-155 enhances innate antiviral immunity against HBV infection in human hepatoma cells. Virol J 2011;8:354. doi: 10.1186/1743-422X-8-354.

[65] Li Y, Xie J, Xu X, Wang J, Ao F, Wan Y, et al. MicroRNA-548 down-regulates host antiviral response via direct targeting of IFN-lambda1. Protein Cell 2013;4:130-141. doi: 10.1007/s13238-012-2081-y.

[66] Jiang X, Kanda T, Wu S, Nakamura M, Miyamura T, Nakamoto $S$, et al. Regulation of microRNA by hepatitis $B$ virus infection and their possible association with control of innate immunity. World J Gastroenterol 2014; 20:7197-7206. doi: 10.3748/wjg.v20.i23.7197. 
[67] Hou ZH, Han QJ, Zhang C, Tian ZG, Zhang J. miR146a impairs the IFNinduced anti-HBV immune response by downregulating STAT1 in hepatocytes. Liver Int 2014;34:58-68. doi: 10.1111/liv.12244.

[68] Liu Y, Zhao JJ, Wang CM, Li MY, Han P, Wang L, et al. Altered expression profiles of microRNAs in a stable hepatitis $B$ virus-expressing cell line. Chin Med J (Engl) 2009;122:10-14.

[69] Momeni M, Hassanshahi G, Arababadi MK, Kennedy D. Ectopic expression of micro-RNA-1, 21 and 125a in peripheral blood immune cells is associated with chronic HBV infection. Mol Biol Rep 2014;41:4833-4837. doi: 10. 1007/s11033-014-3355-7.

[70] Brenner DA, Waterboer T, Choi SK, Lindquist JN, Stefanovic B, Burchardt E, et al. New aspects of hepatic fibrosis. J Hepatol 2000;32:32-38. doi: 10 . 1016/S0168-8278(00)80413-4.

[71] Guo C], Pan Q, Cheng T, Jiang B, Chen GY, Li DG. Changes in microRNAs associated with hepatic stellate cell activation status identify signaling pathways. FEBS J 2009;276:5163-5176. doi: 10.1111/j.1742-4658.2009. 07213.x.

[72] Lakner AM, Steuerwald NM, Walling TL, Ghosh S, Li T, McKillop IH, et al, Inhibitory effects of microRNA $19 \mathrm{~b}$ in hepatic stellate cell-mediated fibrogenesis. Hepatology 2012;56:300-310. doi: 10.1002/hep.25613.

[73] Venugopal SK, Jiang J, Kim TH, Li Y, Wang SS, Torok NJ, et al. Liver fibrosis causes downregulation of miRNA-150 and miRNA-194 in hepatic stellate cells, and their overexpression causes decreased stellate cell activation. Am J Physiol Gastrointest Liver Physiol 2010;298:101-106. doi: 10. 1152/ajpgi.00220.2009.

[74] Roderburg C, Urban GW, Bettermann K, Vucur M, Zimmermann H, Schmidt $\mathrm{S}$, et al. Micro-RNA profiling reveals a role for miR-29 in human and murine liver fibrosis. Hepatology 2011;53:209-218. doi: 10.1002/hep.23922.

[75] Huang CF, Sun CC, Zhao F, Zhang YD, Li DJ. miR-33a levels in hepatic and serum after chronic HBV-induced fibrosis. J Gastroenterol 2015;50:480490. doi: 10.1007/s00535-014-0986-3.

[76] Li Z, Zhang S, Huang C, Zhang W, Hu Y, Wei B. MicroRNAome of splenic macrophages in hypersplenism due to portal hypertension in hepatitis $B$ virus-related cirrhosis. Exp Biol Med (Maywood) 2008;233:1454-1461. doi: $10.3181 / 0711-R M-321$.

[77] Neuveut C, Wei Y, Buendia MA. Mechanisms of HBV-related hepatocarcinogenesis. J Hepatol 2010;52:594-604. doi: 10.1016/j.jhep.2009.10.033.

[78] Lujambio A, Lowe SW. The microcosmos of cancer. Nature 2012;482 347-355. doi: 10.1038/nature10888.

[79] Ura S, Honda M, Yamashita T, Ueda T, Takatori H, Nishino R, et al. Differential microRNA expression between hepatitis $B$ and hepatitis $C$ leading disease progression to hepatocellular carcinoma. Hepatology 2009;49: 1098-1112. doi: 10.1002/hep.22749.

[80] Fan CG, Wang CM, Tian C, Wang Y, Li L, Sun WS, et al. miR-122 inhibits viral replication and cell proliferation in hepatitis B virus-related hepatocellular carcinoma and targets NDRG3. Oncol Rep 2011;26:1281-1286. doi: 10. 3892/or.2011.1375.

[81] Li C, Wang Y, Wang S, Wu B, Hao J, Fan H, et al. Hepatitis B virus mRNAmediated miR-122 inhibition upregulates PTTG1-binding protein, which promotes hepatocellular carcinoma tumor growth and cell invasion. J Virol 2013;87:2193-2205. doi: 10.1128/JVI.02831-12.

[82] Fornari F, Gramantieri L, Giovannini C, Veronese A, Ferracin M, Sabbioni S, et al. MiR-122/cyclin G1 interaction modulates p53 activity and affects doxorubicin sensitivity of human hepatocarcinoma cells. Cancer Res 2009;69: 5761-5767. doi: 10.1158/0008-5472.CAN-08-4797.

[83] Wu Q, Liu HO, Liu YD, Liu WS, Pan D, Zhang WJ, et al. Decreased expression of Hnf4alpha/miR-122 axis in hepatitis B virus-associated hepatocellular carcinoma enhances potential oncogenic GALNT10 activity. J Biol Chem 2014;290:1170-1185. doi: 10.1074/jbc.M114.601203.

[84] Song K, Han C, Zhang J, Lu D, Dash S, Feitelson M, et al. Epigenetic regulation of MicroRNA-122 by peroxisome proliferator activated receptorgamma and hepatitis b virus $X$ protein in hepatocellular carcinoma cells. Hepatology 2013;58:1681-1692. doi: 10.1002/hep.26514.

[85] Wei X, Xiang T, Ren G, Tan C, Liu R, Xu X, et al. miR-101 is down-regulated by the hepatitis $B$ virus $x$ protein and induces aberrant DNA methylation by targeting DNA methyltransferase 3A. Cell Signal 2013;25:439-446. doi: 10.1016/j.cellsig.2012.10.013.

[86] Su H, Yang JR, Xu T, Huang J, Xu L, Yuan Y, et al. MicroRNA-101, downregulated in hepatocellular carcinoma, promotes apoptosis and suppresses tumorigenicity. Cancer Res 2009;69:1135-1142. doi: 10.1158/0008-5472. CAN-08-2886.

[87] Xu X, Fan Z, Kang L, Han J, Jiang C, Zheng X, et al. Hepatitis B virus X protein represses miRNA-148a to enhance tumorigenesis. J Clin Invest 2013;123:630-645. doi: 10.1172/JCI64265.

[88] Wang Y, Lu Y, Toh ST, Sung WK, Tan P, Chow P, et al. Lethal-7 is downregulated by the hepatitis $\mathrm{B}$ virus $\mathrm{x}$ protein and targets signal transducer and activator of transcription 3. J Hepatol 2010;53:57-66. doi: 10.1016/j. jhep.2009.12.043.

[89] Zhang T, Zhang J, Cui M, Liu F, You X, Du Y, et al. Hepatitis B virus X protein inhibits tumor suppressor miR-205 through inducing hypermethylation of
miR-205 promoter to enhance carcinogenesis. Neoplasia 2013;15: 1282-1291.

[90] Wei X, Tan C, Tang C, Ren G, Xiang T, Qiu Z, et al. Epigenetic repression of miR-132 expression by the hepatitis $B$ virus $x$ protein in hepatitis $B$ virusrelated hepatocellular carcinoma. Cell Signal 2013;25:1037-1043. doi: 10. 1016/j.cellsig.2013.01.019.

[91] Chen X, Zhang L, Zhang T, Hao M, Zhang X, Zhang J, et al. Methylationmediated repression of microRNA 129-2 enhances oncogenic SOX4 expression in HCC. Liver Int 2013;33:476-486. doi: 10.1111/liv.12097.

[92] Wu CS, Yen CJ, Chou RH, Chen JN, Huang WC, Wu CY, et al. Downregulation of microRNA-15b by hepatitis $B$ virus $X$ enhances hepatocellular carcinoma proliferation via fucosyltransferase 2 -induced Globo $\mathrm{H}$ expression. Int J Cancer 2014;134:1638-1647. doi: 10.1002/ijc.28501.

[93] Shi C, Xu X. MicroRNA-22 is down-regulated in hepatitis B virus-related hepatocellular carcinoma. Biomed Pharmacother 2013;67:375-380. doi: 10.1016/j.biopha.2013.03.002.

[94] Ji J, Shi J, Budhu A, Yu Z, Forgues M, Roessler S, et al. MicroRNA expression, survival, and response to interferon in liver cancer. N Engl J Med 2009;361: 1437-1447. doi: 10.1056/NEJMoa0901282.

[95] Wang CM, Wang Y, Fan CG, Xu FF, Sun WS, Liu YG, et al. miR-29c targets TNFAIP3, inhibits cell proliferation and induces apoptosis in hepatitis B virus-related hepatocellular carcinoma. Biochem Biophys Res Commun 2011; 411:586-592. doi: 10.1016/j.bbrc.2011.06.191.

[96] Gao P, Wong CC, Tung EK, Lee JM, Wong CM, Ng IO. Deregulation of microRNA expression occurs early and accumulates in early stages of HBV-associated multistep hepatocarcinogenesis. J Hepatol 2011;54: 1177-1184. doi: 10.1016/j.jhep.2010.09.023.

[97] Yang XW, Zhang LJ, Huang XH, Chen LZ, Su Q, Zeng WT, et al. miR-145 suppresses cell invasion in hepatocellular carcinoma cells: miR-145 targets ADAM17. Hepatol Res 2014;44:551-559. doi: 10.1111/hepr.12152.

[98] Fornari F, Milazzo M, Chieco P, Negrini M, Calin GA, Grazi GL, et al. MiR-199a$3 p$ regulates $m T O R$ and $c-$ Met to influence the doxorubicin sensitivity of human hepatocarcinoma cells. Cancer Res 2010;70:5184-5193. doi: 10. 1158/0008-5472.CAN-10-0145.

[99] Connolly E, Melegari M, Landgraf P, Tchaikovskaya T, Tennant BC, Slagle BL, et al. Elevated expression of the miR-17-92 polycistron and miR-21 in hepadnavirus-associated hepatocellular carcinoma contributes to the malignant phenotype. Am J Pathol 2008;173:856-864. doi: 10.2353/ ajpath.2008.080096.

[100] Aguda BD, Kim Y, Piper-Hunter MG, Friedman A, Marsh CB. MicroRNA regulation of a cancer network: consequences of the feedback loops involving miR-17-92, E2F, and Myc. Proc Natl Acad Sci USA 2008;105:19678-19683. doi: 10.1073/pnas.0811166106.

[101] Li CH, Xu F, Chow S, Feng L, Yin D, Ng TB, et al. Hepatitis B virus X protein promotes hepatocellular carcinoma transformation through interleukin- 6 activation of microRNA-21 expression. Eur J Cancer 2014;50:2560-2569. doi: 10.1016/j.ejca.2014.07.008.

[102] Bandopadhyay M, Banerjee A, Sarkar N, Panigrahi R, Datta S, Pal A, et al. Tumor suppressor micro RNA miR-145 and onco micro RNAs miR-21 and miR-222 expressions are differentially modulated by hepatitis $B$ virus $X$ protein in malignant hepatocytes. BMC Cancer 2014;14:721. doi: 10. 1186/1471-2407-14-721.

[103] Qiu X, Dong S, Qiao F, Lu S, Song Y, Lao Y, et al. HBx-mediated miR-21 upregulation represses tumor-suppressor function of PDCD4 in hepatocellular carcinoma. Oncogene 2013;32:3296-3305. doi: 10.1038/onc.2013. 150.

[104] Kong G, Zhang J, Zhang S, Shan C, Ye L, Zhang X. Upregulated microRNA29 a by hepatitis $B$ virus $X$ protein enhances hepatoma cell migration by targeting PTEN in cell culture model. PLoS One 2011;6:e19518. doi: 10. 1371/journal.pone.0019518.

[105] Zhang X, Liu S, Hu T, He Y, Sun S. Up-regulated microRNA-143 transcribed by nuclear factor kappa $B$ enhances hepatocarcinoma metastasis by repressing fibronectin expression. Hepatology 2009;50:490-499. doi: 10. 1002/hep. 23008

[106] Yang L, Ma Z, Wang D, Zhao W, Chen L, Wang G. MicroRNA-602 regulating tumor suppressive gene RASSF1A is overexpressed in hepatitis B virusinfected liver and hepatocellular carcinoma. Cancer Biol Ther 2010;9: 803-808. doi: 10.4161/cbt.9.10.11440.

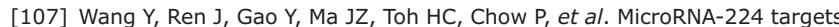
SMAD family member 4 to promote cell proliferation and negatively influence patient survival. PLoS One 2013;8:e68744. doi: 10.1371/journal. pone. 0068744

[108] Zou C, Li Y, Cao Y, Zhang J, Jiang J, Sheng Yet al. Up-regulated MicroRNA$181 \mathrm{a}$ induces carcinogenesis in hepatitis B virus-related hepatocellular carcinoma by targeting E2F5. BMC Cancer 2014;14:97. doi: 10.1186/ 1471-2407-14-97.

[109] Zou C, Chen J, Chen K, Wang S, Cao Y, Zhang J, et al. Functional analysis of miR-181a and Fas involved in hepatitis B virus-related hepatocellular carcinoma pathogenesis. Exp Cell Res 2014;331:352-361. doi: 10.1016/j. yexcr.2014.11.007. 
[110] Wu X], Li Y, Liu D, Zhao LD, Bai B, Xue MH. miR-27a as an oncogenic microRNA of hepatitis B virus- related hepatocellular carcinoma. Asian Pac J Cancer Prev 2013;14:885-889.

[111] Xie Q, Chen X, Lu F, Zhang T, Hao M, Wang $Y$, et al. Aberrant expression of microRNA 155 may accelerate cell proliferation by targeting sex-determining region $Y$ box 6 in hepatocellular carcinoma. Cancer 2012;118:24312442. doi: $10.1002 / \mathrm{cncr} .26566$.

[112] Cortez MA, Calin GA. MicroRNA identification in plasma and serum: a new tool to diagnose and monitor diseases. Expert Opin Biol Ther 2009;9:703711. doi: $10.1517 / 14712590902932889$.

[113] Zhang Y, Jia Y, Zheng R, Guo Y, Wang Y, Guo H, et al. Plasma microRNA-122 as a biomarker for viral-, alcohol-, and chemical-related hepatic diseases. Clin Chem 2010;56:1830-1838. doi: 10.1373/clinchem.2010.147850.

[114] Xu J, Wu C, Che X, Wang L, Yu D, Zhang T, et al. Circulating microRNAs, miR-21, miR-122, and miR-223, in patients with hepatocellular carcinoma or chronic hepatitis. Mol Carcinog 2011;50:136-142. doi: 10.1002/mc. 20712.

[115] Qi P, Cheng SQ, Wang H, Li N, Chen YF, Gao CF. Serum microRNAs as biomarkers for hepatocellular carcinoma in Chinese patients with chronic hepatitis B virus infection. PLoS One 2011;6:e28486. doi: 10.1371/journal. pone. 0028486.

[116] Giray BG, Emekdas G, Tezcan S, Ulger M, Serin MS, Sezgin O, et al. Profiles of serum microRNAs; miR-125b-5p and miR223-3p serve as novel biomarkers for HBV-positive hepatocellular carcinoma. Mol Biol Rep 2014; 41:4513-4519. doi: 10.1007/s11033-014-3322-3.

[117] Wang JY, Mao RC, Zhang YM, Zhang Y], Liu HY, Qin YL, et al. Serum microRNA-124 is a novel biomarker for liver necroinflammation in patients with chronic hepatitis B virus infection. J Viral Hepat 2015;22:128-136. doi: $10.1111 /$ jvh.12284.

[118] Huang C, Zheng JM, Cheng Q, Yu KK, Ling QX, Chen MQ, et al. Serum microRNA-29 levels correlate with disease progression in patients with chronic hepatitis B virus infection. J Dig Dis 2014;15:614-621. doi: 10. 1111/1751-2980.12185.
[119] Li L, Guo Z, Wang J, Mao Y, Gao O. Serum miR-18a: a potential marker for hepatitis B virus-related hepatocellular carcinoma screening. Dig Dis Sci 2012;57:2910-2916. doi: 10.1007/s10620-012-2317-y.

[120] Xie Y, Yao Q, Butt AM, Guo J, Tian Z, Bao X, et al. Expression profiling of serum microRNA-101 in HBV-associated chronic hepatitis, liver cirrhosis, and hepatocellular carcinoma. Cancer Biol Ther 2014;15:1248-1255. doi: $10.4161 / \mathrm{cbt} .29688$

[121] Zhou J, Yu L, Gao X, Hu J, Wang J, Dai Z, et al. Plasma microRNA panel to diagnose hepatitis B virus-related hepatocellular carcinoma. J Clin Oncol 2011;29:4781-4788. doi: 10.1200/JCO.2011.38.2697.

[122] Li LM, Hu ZB, Zhou ZX, Chen X, Liu FY, Zhang JF, et al. Serum microRNA profiles serve as novel biomarkers for HBV infection and diagnosis of HBVpositive hepatocarcinoma. Cancer Res 2010;70:9798-9807. doi: 10. 1158/0008-5472.CAN-10-1001.

[123] Novellino L, Rossi RL, Bonino F, Cavallone D, Abrignani S, Pagani M, et al. Circulating hepatitis B surface antigen particles carry hepatocellular microRNAs. PLoS One 2012;7:e31952. doi: 10.1371/journal.pone.0031952.

[124] Ely A, Naidoo T, Mufamadi S, Crowther C, Arbuthnot P. Expressed anti-HBV primary microRNA shuttles inhibit viral replication efficiently in vitro and in vivo. Mol Ther 2008;16:1105-1112. doi: 10.1038/mt.2008.82.

[125] Chattopadhyay S, Ely A, Bloom K, Weinberg MS, Arbuthnot P. Inhibition of hepatitis $B$ virus replication with linear DNA sequences expressing antiviral micro-RNA shuttles. Biochem Biophys Res Commun 2009;389:484-489. doi: 10.1016/j.bbrc.2009.09.004.

[126] Mowa MB, Crowther C, Ely A, Arbuthnot P. Inhibition of hepatitis B virus replication by helper dependent adenoviral vectors expressing artificial anti-HBV pri-miRs from a liver-specific promoter. Biomed Res Int 2014; 2014:718743. doi: 10.1155/2014/718743.

[127] Schiffer JT, Aubert M, Weber ND, Mintzer E, Stone D, Jerome KR. Targeted DNA mutagenesis for the cure of chronic viral infections. J Virol 2012;86: 8920-8936. doi: 10.1128/JVI.00052-12.

[128] Xiangji L, Feng X, Qingbao C, Weifeng T, Xiaoqing J, Baihe Z, et al. Knockdown of HBV surface antigen gene expression by a lentiviral microRNAbased system inhibits HBV replication and HCC growth. J Viral Hepat 2011;18:653-660. doi: 10.1111/j.1365-2893.2010.01346.x. 